\title{
Pharmacological potential of tocotrienols: a review
}

\author{
Haseeb Ahsan', Amjid Ahad², Jahangir lqbal ${ }^{3}$ and Waseem A Siddiqui ${ }^{2^{*}}$
}

\begin{abstract}
Tocotrienols, members of the vitamin E family, are natural compounds found in a number of vegetable oils, wheat germ, barley, and certain types of nuts and grains. Like tocopherols, tocotrienols are also of four types viz. alpha, beta, gamma and delta. Unlike tocopherols, tocotrienols are unsaturated and possess an isoprenoid side chain. Tocopherols are lipophilic in nature and are found in association with lipoproteins, fat deposits and cellular membranes and protect the polyunsaturated fatty acids from peroxidation reactions. The unsaturated chain of tocotrienol allows an efficient penetration into tissues that have saturated fatty layers such as the brain and liver. Recent mechanistic studies indicate that other forms of vitamin E, such as $\gamma$-tocopherol, $\delta$-tocopherol, and $\gamma$-tocotrienol, have unique antioxidant and anti-inflammatory properties that are superior to those of a-tocopherol against chronic diseases. These forms scavenge reactive nitrogen species, inhibit cyclooxygenase- and 5-lipoxygenase-catalyzed eicosanoids and suppress proinflammatory signalling, such as NF-KB and STAT. The animal and human studies show tocotrienols may be useful against inflammation-associated diseases. Many of the functions of tocotrienols are related to its antioxidant properties and its varied effects are due to it behaving as a signalling molecule. Tocotrienols exhibit biological activities that are also exhibited by tocopherols, such as neuroprotective, anti-cancer, anti-inflammatory and cholesterol lowering properties. Hence, effort has been made to compile the different functions and properties of tocotrienols in experimental model systems and humans. This article constitutes an in-depth review of the pharmacology, metabolism, toxicology and biosafety aspects of tocotrienols. Tocotrienols are detectable at appreciable levels in the plasma after supplementations. However, there is inadequate data on the plasma concentrations of tocotrienols that are sufficient to demonstrate significant physiological effect and biodistribution studies show their accumulation in vital organs of the body. Considering the wide range of benefits that tocotrienols possesses against some common human ailments and having a promising potential, the experimental analysis accounts for about a small fraction of all vitamin $\mathrm{E}$ research. The current state of knowledge deserves further investigation into this lesser known form of vitamin $\mathrm{E}$.
\end{abstract}

Keywords: Dietary tocotrienols, Pharmacology, Antioxidant, Anti-inflammatory, Hypolipidemic, Hypoglycaemic, Anti-cancer, Cardioprotective

\section{Introduction}

Evans and Bishop, in 1922, discovered that dietary supplements with alfalfa leaves (rich in vitamin E) prevent placental hemorrhage and reverse dietary sterility in rats [1]. Evans and his associates [2] isolated the compounds of vitamin E family and named them tocopherols (Greek: Tocos-child birth; pheros- to bear; ol-alcohol). While alpha-tocopherol was the first vitamin $\mathrm{E}$ isomer to be recognized, eight chemically distinct isomers are now known, consisting of alpha $(\alpha)$, beta $(\beta)$, gamma $(\gamma)$ and delta $(\delta$ )-tocopherols and $\alpha, \beta, \gamma$ and $\delta$-tocotrienols (T3),

\footnotetext{
* Correspondence: wasiddiqui01@gmail.com

${ }^{2}$ Department of Biochemistry, Jamia Hamdard (Hamdard University), New Delhi 110062, India

Full list of author information is available at the end of the article
}

all of them are referred to as vitamin E. The tocopherols are saturated forms of vitamin $\mathrm{E}$, whereas the tocotrienols are unsaturated and possess an isoprenoid side chain (Table 1). The name "tocotrienol" was first suggested by Dr. Banyan, for the isomers of vitamin E, with isoprenoid side chain present in nature, when isolated from the latex of the rubber plant, Havea brasiliensis [3]. Tocotrienols attracted no real attention until the 1980's and 1990's when their cholesterol-lowering potential [4] and anticancer effects were described [5,6]. This review article will take a closer look at the various functions of tocotrienol by providing numerous potential evidences on how it may be protective against these chronic diseases. Tocotrienols are found in certain cereals and vegetables such as palm oil, rice bran oil, coconut oil, barley germ, wheat germ and 
Table 1 Structures of various homologs of tocotrienols

\begin{tabular}{lllll}
\hline Type & R1 & R2 & R3 & Structure \\
\hline alpha(a)-Tocotrienol & Me & Me & $M e$ &
\end{tabular}

beta( $(\beta)$-Tocotrienol $\mathrm{Me}$
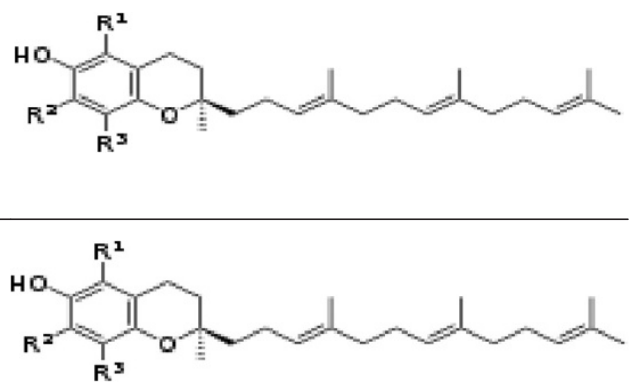

annatto $[7,8]$. Palm oil and rice bran oil contain particularly higher amounts of tocotrienols $(940 \mathrm{mg} / \mathrm{kg}$ and $465 \mathrm{mg} / \mathrm{kg}$, respectively) [9]. Other sources of tocotrienols include grape fruit seed oil, oats, hazelnuts, maize, olive oil, Buckthorn berry, rye, flax seed oil, poppy seed oil and sunflower oil.

Tocotrienols possess powerful neuroprotective, antioxidant, anti-cancer and cholesterol lowering properties that often differ from the properties of tocopherols [10]. Micromolar amounts of tocotrienol suppress the activity of HMG-CoA reductase, the hepatic enzyme responsible for the synthesis of cholesterol [11,12]. Tocotrienols are thought to have more potent antioxidant properties than $\alpha$-tocopherol $[13,14]$. The unsaturated side chain of tocotrienol allows for more efficient penetration into tissues that have saturated fatty layers such as the brain and liver [15]. Experimental research examining the antioxidant, free radical scavenging, effects of tocopherol and tocotrienols have found that tocotrienols appear superior due to their better distribution in the lipid layers of the cell membrane [16]. One major conclusion often used to undermine tocotrienol research is the relative inferiority of the bioavailability of orally taken tocotrienols as compared to that of $\alpha$-tocopherol. The hepatic $\alpha$-tocopherol transfer protein $(\alpha-\mathrm{TTP})$, together with the tocopherolassociated proteins (TAP) is responsible for the endogenous accumulation of natural $\alpha$-tocopherol.
Tocotrienols are absorbed, in the same way as other vitamin E compounds, alongwith fat, in the small intestine, after being cleaved by the enzyme esterase, located in the stomach lining. Bile salts are necessary for the absorption. It is then packaged into chylomicrons and then transported in the lymphatic system. The $\alpha$-tocotrienol appears to be better absorbed than the other forms of tocotrienol. In the bloodstream, tocotrienols are exposed to the oxidative free radicals and therefore perform most of their antioxidant activity. Tissue uptake takes place either with the help of lipoprotein lipases, digesting the lipoprotein constituents, or by receptor mediated endocytosis of lipoprotein. Lipoprotein lipase degrades lipoproteins to remnant particles which are then taken up by liver or peripheral tissues by receptor mediated endocytosis. Tocotrienols enter a variety of different tissue types, with adipose and adrenal gland having the highest levels. Vitamins can be stored in the tissue for long periods of time because of their exceedingly slow turnover rate. Vitamin $\mathrm{E}$ is oxidized after it has performed its antioxidant function. It is converted to its hydroquinone form in a P450 dependent manner before being eliminated from the body through faeces. Hydroquinone form binds with glucuronic acid and mixes with bile for removal through faeces. Despite the promising potential of tocotrienol, the experimental analysis accounts for only a small fraction of all vitamin E research. However, 
biologists are increasingly realizing the importance of this minor and unique vitamin $\mathrm{E}$ isomer [16].

Various minerals and vitamins are present in a variety of food products and available as dietary supplements. Selenium (Se) is an essential micronutrient that occurs predominantly as selenomethionine (SeMet), whereas vitamin E (or a-tocopherol) is a fat-soluble physiological antioxidant, both of which are required for normal health [17-19]. The Se and vitamin E are essential components of the human diet and have been studied as antioxidants and potential therapeutic agents for a variety of human diseases. Various formulations of Se and vitamin $\mathrm{E}$ have been shown to possess a therapeutic and preventive effect against prostate cancer ( $\mathrm{PCa}$ ) cells [20].

The motivation for the use of vitamin $\mathrm{E}$ and Se for the prevention of PCa comes from clinical trial data. Vitamin $\mathrm{E}$ was shown to be a promising candidate for $\mathrm{PCa}$ prevention in the $\alpha$-Tocopherol $\beta$-Carotene Cancer Prevention Study, a controlled smoking trial where $\alpha$-tocopherol reduced $\mathrm{PCa}$ incidence by $32 \%$ and mortality by $41 \%$ [21]. The SUpplementation en VItamines et Mineraux AntioXidants (SUVIMAX) study found a significant reduction in $\mathrm{PCa}$ rates among men receiving a multivitamin containing $30 \mathrm{mg}$ vitamin $\mathrm{E}$, although the protective effect could not be attributed to any specific micronutrient [22]. In contrast, the Heart Outcomes Prevention Evaluation (HOPE) trial, the Heart Protection Study, the NIH-AARP Diet and Health Study and the Cancer Prevention Study II Nutrition Cohort donot support a general protective effect of $\alpha$-tocopherol supplement use for PCa prevention [23-26].

Therefore, the Selenium and Vitamin E Cancer Prevention Trial (SELECT), was designed to test a prostate cancer chemoprevention hypothesis using oral Se and vitamin $\mathrm{E}$ supplementation in disease-free volunteers. Initiated in 2001, the SELECT was a phase III, randomized, placebo-controlled human trial to investigate the PCa chemopreventive effects of Se, vitamin $\mathrm{E}$ or their combination [27]. SELECT was among the largest clinical chemoprevention trials ever, with an enrollment of more than 35,000 men and an intended follow-up of up to 12 years [27]. SELECT was predicated on basic and clinical research including secondary endpoint data from cancer prevention studies that implied Se and vitamin E supplements could be useful in reducing PCa risk. However, the trial was prematurely terminated in 2008, 18 months before its intended minimum follow-up length. The Se and vitamin $\mathrm{E}$ doses and formulations used in SELECT were found to be ineffective, and concern was raised about a possible trend in developing type 2 diabetes mellitus among the study participants taking Se [27]. Further, a statistically nonsignificant increased risk of $\mathrm{PCa}$ was also seen in the vitamin $\mathrm{E}$ group participants. Unfortunately, despite the perceived suitability of $\mathrm{PCa}$ for chemoprevention and the considerable evidence suggesting the usefulness of Se and vitamin E for PCa prevention, SELECT failed to show a positive effect. Hence, the SELECT trial was terminated early because of the safety concerns and negative data for the formulations and doses given [28].

The biological activity of vitamin $\mathrm{E}$ has generally been associated with its well-defined antioxidant property, specifically against lipid peroxidation in biological membranes. In the vitamin E group, a-tocopherol is considered to be the most active form. Moreover, tocotrienol has been shown to possess novel hypocholesterolemic effects together with an ability to reduce the atherogenic apolipoprotein B and lipoprotein(a) plasma levels. In addition, tocotrienol has been suggested to have an antithrombotic and anti-tumor effect indicating that tocotrienol may serve as an effective agent in the prevention and/or treatment of cardiovascular disease and cancer. The physiological activity of tocotrienol suggests it to be superior than a-tocopherol in many pathophysiological conditions. Hence, the role of tocotrienol in the prevention of cardiovascular disease and cancer may have significant clinical implications. Additional studies on its mechanism of action, as well as, long-term intervention studies from the pharmacological point-of-view are required to elucidate its function [29].

\section{Biochemical functions}

Vitamin $\mathrm{E}$ is not a single agent but is at least eight "vitamers," named tocochromanols and can be either "tocopherols" or "tocotrienols". They are further assigned Greek letter prefixes by degree of methyl substitution, that is, $\alpha$-tocopherol (with three chiral centers) exists naturally as the $\left(2 R, 4^{\prime} R, 8^{\prime} R\right)$ stereoisomer and is synthesized as allracemic or (2RS,4'RS,8'RS) product [30]. In 1943, Joffe and Harris demonstrated varying potencies of the eight forms of vitamins [31]. It is known that $\alpha$-tocopherol is taken up in the human liver by hepatic transfer proteins and some tocopherol stereoisomers penetrate cell membranes more easily $[31,32]$. The $2 \mathrm{R}$ isomers of $\alpha$-tocopherol are putatively used to establish the vitamin $E$ requirement [33]. As commercial dietary supplements, both natural (RRR) and synthetic (all-rac) $\alpha$-tocopheryl esters (acetate or succinate) are available and extensively used. Lee $e t$ al. [34] showed that vitamin E succinate has a distinct anti-prostaglandin effect in human lung epithelial cells. Vitamin E is relatively safe for consumption even at high dosages, since a 3,200-IU dose was well tolerated by adults in short-term studies [35].

One of the most significant differences between $\alpha \mathrm{T}$ and other forms of vitamin $\mathrm{E}$ is that in contrast to $\alpha \mathrm{T}$, which is mostly retained in tissues because of preferential binding by $\alpha$-TTP, large quantities of other forms of vitamin $\mathrm{E}$ are readily metabolized by CYP4F2-initiated 
$\omega$-oxidation of the side chain to generate carboxychromanols and conjugated counterparts. Short-chain carboxychromanols such as CEHCs are excreted in the urine and $\gamma$-CEHC has been shown to have natriuretic activities [36]. Long-chain carboxychromanols, especially $13^{\prime}$-COOHs, are found in tissues and faeces in animals supplemented with $\gamma \mathrm{T}, \delta \mathrm{T}$, and $\gamma \mathrm{TE}$ [37-40]. The discovery of potent anti-inflammatory [41,42] and anticancer [43] effects of long-chain carboxychromanols represents an exciting research direction and provides new insights into the physiological roles of less tissue-preserved forms of vita$\min \mathrm{E}[44]$.

$\alpha$-tocopherol, the commonly studied isomer of vitamin $E$, has been shown to possess an anti-cancer effect [45-47]. However, the researchers have also started evaluating $\gamma$ tocopherol for its chemopreventive efficacy [45-51]. Interestingly, $\gamma$-tocopherol is being increasingly appreciated to have a better potential than $\alpha$-tocopherol [52]. Studies have shown that the in vitro products of $\gamma$-tocopherol antioxidant reactions differ from those of $\alpha$-tocopherol, with the latter alone forming nitrosating agents when exposed to $\mathrm{NO}_{2}$ [52]. Christen et al. [53] showed that $\gamma$ tocopherol may be required to complement the activity of $\alpha$-tocopherol, suggesting that supplementation of $\alpha$-tocopherol alone may suppress $\gamma$-tocopherol levels. The majority of available experimental data on vitamin $\mathrm{E}$ for suppressing PCa has been obtained with $\alpha$-tocopherol, leaving the possibility that other vitamin $\mathrm{E}$ isomers may possess better chemopreventive or anticancer potential against $\mathrm{PCa}$, but which needs to be explored further [28].

All tocopherols and tocotrienols are potent antioxidants with lipoperoxyl radical-scavenging activities. Only until recently, most research on vitamin $\mathrm{E}$ has primarily focused on $\alpha \mathrm{T}$ [54], because $\alpha \mathrm{T}$ is the predominant form of vitamin $\mathrm{E}$ in tissues and low intake of this form results in vitamin E deficiency-associated ataxia [55]. However, many human and animal studies on $\alpha \mathrm{T}$ supplementation have yielded disappointing outcomes regarding its protective role in prevention or treatment of chronic diseases including cardiovascular diseases and cancer [56,57]. On the other hand, recent mechanistic studies combined with preclinical animal models have indicated that compared with $\alpha \mathrm{T}$, other forms of vitamin $\mathrm{E}$ appear to have different and superior biological properties that may be useful for prevention and therapy against chronic diseases. Furthermore, emerging evidence suggests that some long-chain vitamin $\mathrm{E}$ metabolites have even stronger anti-inflammatory effects than their vitamin precursors. These metabolites may be novel antiinflammatory agents and may contribute to beneficial effects of vitamin $\mathrm{E}$ forms in vivo. Here we discuss recent developments in the field of non- $\alpha \mathrm{T}$ forms of vitamin $\mathrm{E}$ with respect to their metabolism and antioxidant and anti-inflammatory effects [44].
Most of the functions of tocotrienols are related to its antioxidant property in animals. It prevents the nonenzymatic oxidations of various cell components (e.g. unsaturated fatty acids) by molecular oxygen and free radicals such as superoxide $\left(\mathrm{O}_{2}^{-}\right)$and hydrogen peroxide $\left(\mathrm{H}_{2} \mathrm{O}_{2}\right)$. The various biochemical functions of tocotrienols are related either directly or indirectly to its antioxidant property. They are essential for membrane structure and integrity of the cell [58]. Tocotrienols prevent the peroxidation of polyunsaturated fatty acids in various tissues and membranes and protects the red blood cells from hemolysis by oxidizing agents [59]. It increases the synthesis of heme by enhancing the activity of enzymes $\delta$-aminolevulinic acid (ALA) synthase and ALA dehydratase. It is required for cellular respiration through electron transport chain and is believed to stabilize coenzyme Q. It prevents the oxidation of vitamin $\mathrm{A}$ and carotenes and also LDL and thus may be helpful in the prevention of some chronic diseases $[9,59]$. Tocotrienols also protects the liver from being damaged by toxic compounds such as $\mathrm{CCL}_{4}$.

\section{Pharmacological properties}

Tocotrienols have a very broad range of medicinal properties and are used as antioxidant, analgesic, antiinflammatory, antibacterial, antipyretic, antithrombotic, anticancer, cardioprotective, hepatoprotective, hypoglycemic, and nephroprotective, as discussed below. The pharmacological potential of tocotrienols has also been summarized in Table 2.

\section{Anti-cancer effects}

The anticancer properties of tocotrienols are well known and documented [60-76]. Tocotrienols not only suppress cancer-cell proliferation, but also induces apoptosis in cancer cells. It has been reported that $\gamma$ - and $\delta$-tocotrienols exhibit greater anticancer activity than $\alpha$ - or $\beta$-tocotrienols [76-78]. The mechanism of anticancer effects of tocotrienols has been worked out $[5,79,80]$. They exert anti-cancer activity on cancer cells by cell cycle arrest through induction of cell cycle inhibitory protein and decreased expression of cyclin dependent kinase $[64,65,79]$. Tocotrienols also work as an anticancer agent by inhibiting angiogenesis $[81,82]$ or by enhancing immunity and inhibiting tumor cell migration [71]. Tocotrienol induces cell-cycle arrest and mitochondriamediated apoptosis in human pancreatic cancer cells $[68,70,75,83]$. It has also been shown to inhibit the tumor cell growth by suppressing HMG-CoA reductase activity [84]. It has been shown to induce apoptosis in stomach cancer cells through down-regulation of the RafERK signaling pathway [69]. Tocotrienol significantly activated caspase-dependent programmed cell death in skin and pancreatic cells $[73,76] . \gamma$ - and $\delta$-tocotrienols derived 
Table 2 Biological properties of tocotrienols

\begin{tabular}{|c|c|c|c|c|}
\hline S.No. & Protective activity & Tocotrienol type & Proposed mechanism of action & References \\
\hline \multirow[t]{9}{*}{1.} & Anti-cancer & $Y-T_{3}$ & $\begin{array}{l}\text { Inhibition of NF-KB, TGF- } \beta \text { and P38 signalling } \\
\text { pathways }\end{array}$ & {$[8,143]$} \\
\hline & & $Y-T_{3}, \delta-T_{3}$ & Induction and potentiation of apoptosis & {$[20,22,31,144,145]$} \\
\hline & & $a-T_{3}, Y-T_{3}, \delta-T_{3}$ & Activation of caspases & {$[31,34,61,145,146]$} \\
\hline & & $Y-T_{3}, \delta-T_{3}$ & Down-regulation of Bcl-2 and cyclin D & [61] \\
\hline & & $a-T_{3}, \gamma-T_{3}$ & Suppression of HMGR activity & [44] \\
\hline & & TRF from palm oil & Induction of DNA fragmentation & [18] \\
\hline & & $a-T_{3}, \delta-T_{3}$ & Inhibition of angiogenesis & [55] \\
\hline & & $\gamma-T_{3}, \delta-T_{3}$ & $\begin{array}{l}\text { Inhibition of cell proliferation through } \\
\text { cell cycle arrest }\end{array}$ & {$[25,33]$} \\
\hline & & $Y-T_{3}, \delta-T_{3}$ & Down-regulation of Raf/Erk pathway & [27] \\
\hline \multirow[t]{7}{*}{2.} & Anti-diabetic & TRF from palm oil and rice bran oil & $\begin{array}{l}\text { Prevents the formation of advanced } \\
\text { glycationendproducts in diabetic rats }\end{array}$ & [72] \\
\hline & & $a-T_{3}, Y-T_{3}, \delta-T_{3}$ & $\begin{array}{l}\text { Reduces hyperglycemia and hyperlipidemia } \\
\text { in diabetic rats }\end{array}$ & [73] \\
\hline & & $a-T_{3}, y-T_{3}, \delta-T_{3}$ & Inhibition of NF-kB signalling pathway & [75] \\
\hline & & $a-T_{3}, Y-T_{3}, \delta-T_{3}$ & Inhibition of oxidative-nitrosative stress & [120] \\
\hline & & $a-T_{3}, y-T_{3}, \delta-T_{3}$ & $\begin{array}{l}\text { Inhibition of TNF- } \alpha \text {, IL-1 } \beta, \text { TGF- } \beta 1 \text { and } \\
\text { caspase-3 activity }\end{array}$ & {$[74,77]$} \\
\hline & & TRF from palm oil and rice bran oil & Reduction of glucose-insulin index & {$[79,80]$} \\
\hline & & $a-T_{3}, y-T_{3}, \delta-T_{3}$ & Increase in insulin sensitivity & {$[59,81,83]$} \\
\hline \multirow[t]{3}{*}{3.} & Anti-inflammatory & $a-T_{3}, Y-T_{3}, \delta-T_{3}$ & $\begin{array}{l}\text { Suppression of NF-kB, TNF-a, IL-1, IL-6, } \\
\mathrm{IL}-8 \text { and iNOS }\end{array}$ & {$[50,56,74,147]$} \\
\hline & & $a-T_{3}, Y-T_{3}, \delta-T_{3}$ & Suppression of cyclooxygenase-2 activity & {$[51,57]$} \\
\hline & & $a-T_{3}, \gamma-T_{3}, \delta-T_{3}$ & Suppression of STAT-3 signalling pathway & {$[29,45]$} \\
\hline \multirow[t]{3}{*}{4.} & Antioxidant & $a-T_{3}, y-T_{3}, \delta-T_{3}$ & Increase in the activity of antioxidant enzymes & {$[59,60,62,65,148]$} \\
\hline & & $\begin{array}{l}\text { TRF from palm oil and rice bran oil, } \\
a-T_{3}, Y-T_{3}, \delta-T_{3}\end{array}$ & Quenching and scavenging of free radicals & {$[63,69,70,79]$} \\
\hline & & $a-T_{3}, y-T_{3}, \delta-T_{3}$ & Inhibition of lipid peroxidation & {$[64,66,68]$} \\
\hline \multirow[t]{3}{*}{5.} & Immuno-stimulatory & $a-T_{3}, \delta-T_{3}$ & Induction of antibody production & {$[99,101]$} \\
\hline & & $a-T_{3}, Y-T_{3}, \delta-T_{3}$ & Induction of IFN- $\gamma$, IL-4, IL-1 $\beta$ production & {$[99,102]$} \\
\hline & & $\delta-T_{3}$ & Suppression of TNF-a & {$[102]$} \\
\hline \multirow[t]{8}{*}{6.} & Cardio-protective & $a-T_{3}, y-T_{3}$ & Inhibition of HMG-CoA reductase activity & {$[10,86,104]$} \\
\hline & & $a-T_{3}, y-T_{3}$ & Inhibition of expression of cell adhesion molecules & [105] \\
\hline & & $a-T_{3}, \gamma-T_{3}$ & Reduction in the levels of blood cholesterol & {$[106,107]$} \\
\hline & & TRF from palm oil and rice bran oil, $\delta-T_{3}$ & Inhibition of lipid peroxidation & {$[41,80]$} \\
\hline & & $Y-T_{3}, \delta-T_{3}$ & Downregulation of c-Src expression & [102] \\
\hline & & $\gamma-T_{3}, \delta-T_{3}$ & Upregulation of phosphorylation of Akt & {$[102]$} \\
\hline & & TRF from palm oil & $\begin{array}{l}\text { Reduction in the production of apolipoprotein B, } \\
\text { platelet derived factor- } 4 \text {, thromboxane B2 }\end{array}$ & [149] \\
\hline & & TRF from palm oil and rice bran oil & Downregulation of TGF- $\beta$ & {$[80]$} \\
\hline \multirow[t]{3}{*}{7.} & Neuro-protective & $a-T_{3}$ & $\begin{array}{l}\text { Inhibition of PP } 60 \text { (c-Src) kinase activity and } \\
\text { phosphorylation of Erk }\end{array}$ & [112] \\
\hline & & $a-T_{3}, y-T_{3}$ & Inhibition of 12-lipoxygenase activity & {$[115,116]$} \\
\hline & & $a-T_{3}, \gamma-T_{3}, \delta-T_{3}$ & Reduction of oxidative stress & [77] \\
\hline
\end{tabular}


Table 2 Biological properties of tocotrienols (Continued)

\begin{tabular}{|c|c|c|c|c|}
\hline \multirow[t]{3}{*}{8.} & Hepato-protective & $a-T_{3}, \gamma-T_{3}$ & $\begin{array}{l}\text { Inhibition of lipid peroxidation } \\
\text { and oxidative damage }\end{array}$ & {$[62,64,65,68]$} \\
\hline & & $\gamma-T_{3}, \delta-T_{3}$ & $\begin{array}{l}\text { Induction of the expression of CYP450, } \\
\text { UGT1A1 nad MDR-protein } 1\end{array}$ & {$[135,136]$} \\
\hline & & $\begin{array}{l}\text { TRF from palm oil and rice bran oil, } \\
a-T_{3}, \gamma-T_{3}, \delta-T_{3}\end{array}$ & Induction of hepatic antioxidant status & {$[59,137,138]$} \\
\hline \multirow[t]{2}{*}{9.} & Nephro-protective & TRF from rice bran oil, $a-T_{3}, y-T_{3}$ & Inhibition of oxidative-nitrosative stress & {$[12,136,141]$} \\
\hline & & TRF from palm oil and rice bran oil, $a-T_{3}, \gamma-T_{3}$ & $\begin{array}{l}\text { Downregulating the expression of NF-KB, } \\
\text { TGF- } \beta, \text { TNF- } a \text { and caspase- } 3\end{array}$ & {$[75,79,80,136,139]$} \\
\hline
\end{tabular}

from palm oil exhibited strong activity against tumor promotion by inhibiting Epstein-Barr virus (EBV) early antigen expression in EBV-genome-carrying human lymphoblastoid cells induced by phorbol ester [9]. Tocotrienols suppressed DMBA-induced mammary tumors and hypercholesterolemia in murine model [85]. It induced apoptosis in human fibroblast cells through TGF-betaFas-JNK-signaling pathways [47]. Gamma-Tocotrienol induced poly (ADP-ribose) polymerase (PARP) cleavage and stimulated a rise in caspase- 3 , caspase- 8 and caspase- 9 activities in human hepatoma Hep3B cells [68]. The antiproliferative activity of tocotrienols are mediated through modulation of growth factors such as vascular endothelial growth factor (VEGF) [82], basic fibroblast growth factor (bFGF) [86] and transforming growth factor-beta (TGF- $\beta$ ) [62], HER2/neu [87], and interleukin-6 (IL-6) [88]. Cyclindependent kinases (CDK2, CDK4, CDK6) and their inhibitors, such as p21, p27 and p53 [60,64] and downregulation of $\mathrm{Rb}$ phosphorylation $[65,66]$ also mediate the growthsuppressive effects of this agent. Downregulation of the telomerase, c-myc, and raf-ERK signaling pathways has been linked to tocotrienol's ability to inhibit cell survival $[69,89]$.

Pancreatic cancer is a leading cause of cancer mortality with less than $5 \%$ of patients surviving 5 years after diagnosis [90]. Several studies have combined natural compounds that inhibit NF-kB, such as genistein, curcumin, fisetin, and green tea, to investigate synergy in treating pancreatic cancer [91-94]. However, translation of these studies to the clinic has been challenging due to the low bioavailability of some of these natural compounds in humans. Tocotrienols, a group of $4\left(\alpha-, \beta-, \delta_{-}\right.$, and $\gamma^{-}$ tocotrienol) unsaturated naturally occurring vitamin $\mathrm{E}$ compounds have received increasing attention for their potential as nontoxic dietary anticancer agents $[95,96]$. Husain et al. [97] has shown that oral administration of $100 \mathrm{mg} / \mathrm{kg} / \mathrm{d}$ of d-tocotrienol to mice resulted in levels that were 10 times higher in pancreas than in subcutaneously implanted tumor tissue, suggesting that these compounds will have reasonable bioavailability for pancreatic tumor intervention [97]. In another study, they investigated the potential of the natural tocotrienols to inhibit pancreatic cancer and NF-kB activation in vitro and in vivo. In addition, they also investigated the potential of the most bioactive tocotrienol to augment gemcitabine activity in vitro and in vivo [98]. Their results show that $\mathrm{d}$ - and g-tocotrienol inhibited NF-kB activity, cell growth, cell survival, and tumor growth in nude mice. It was shown by them that d-tocotrienol augmented gemcitabine activity in vitro and in vivo. The results suggest that inhibition of NF-kB signaling by d-tocotrienol may be an effective approach for the prevention and treatment of pancreatic cancer. Our findings suggest evaluation of NF-kB signaling compounds as an endpoint biomarker in the ongoing phase I trial of d-tocotrienol in patients with pancreatic tumors [98].

Breast cancer is the second most frequent cancer affecting women worldwide after lung cancer. The toxicity associated with chemical drugs has turned the attention toward natural compounds as anticancer agents. Vitamin E derivatives consisting of tocopherols and their analogs namely tocotrienols have been extensively studied due to their remarkable biological properties. While tocopherols have failed to offer protection, tocotrienols, in particular, $\mathrm{a}-, \mathrm{d}-$, and c-tocotrienols alone and in combination have demonstrated anticancer properties. The antiangiogenic, antiproliferative, and apoptotic effect of tocotrienols not only suggests that they are potent antitumor agents but also reinforces the notion that tocotrienols are indeed more than antioxidants [99].

Nesaretnam et al. [100] conducted a double-blinded, placebo-controlled pilot trial to test the effectiveness of adjuvant tocotrienol therapy in combination with tamoxifen for 5 years in women with early breast cancer. Twohundred forty women, aged between 40 and 60 years, with either tumor node metastases (TNM) breast cancer and estrogen receptor (ER)-positive tumors were non-randomly assigned to two groups. The intervention group received tocotrienol-rich fraction (TRF) plus tamoxifen, whereas the control group received placebo plus tamoxifen, for 5 years. From the study, it was found that there is no association between adjuvant tocotrienol therapy and breast cancer-specific survival in women with early breast cancer. Hence, results from the study were not sufficient to indicate a significant association between adjuvant tocotrienol 
therapy and breast cancer survival in women with early breast cancer. However, evidence suggested that tocotrienols have anticancer effects and tamoxifen and tocotrienol in vitro demonstrate synergy. Although a $60 \%$ lower mortality occurred in the intervention group, this result was not statistically significant. Hence, a large randomized trial is certainly warranted in the near future to establish whether tocotrienol adjuvant therapy can significantly improve recurrence or mortality or both [100].

Nesaretnam et al. [99] have demonstrated a mechanism for tocotrienol activity that involves estrogen receptor (ER) signaling. In silico simulations and in vitro binding analyses indicate a high affinity of specific forms of tocotrienols for ERb, but not for ERa. Moreover, they found that specific tocotrienols increase ERb translocation into the nucleus which, in turn, activates the expression of estrogen responsive genes (MIC-1, EGR-1 and Cathepsin D) in breast cancer cells only expressing ERb cells (MDA-MB231) and in cells expressing both ER isoforms (MCF-7). The binding of specific tocotrienol forms to ERb is associated with the alteration of cell morphology, caspase-3 activation, DNA fragmentation, and apoptosis. Furthermore, some clinical trials seem to suggest that tocotrienols in combination may have the potential to extend breast cancer-specific survival.

Advances in chemopreventive approaches would be an immense breakthrough in lowering the mortality rate associated with breast cancer in women. Supplementation or treatment with palm tocotrienols has shown encouraging results mainly from in vitro and in vivo studies. Hence, tThe studies conducted by Nesaretnam et al. [99] demonstrated that tocotrienols have convincing potential in suppressing and inhibiting the growth of mammary tumor cells. Combined treatment with statins, celecoxib, and tamoxifen resulted in a significantly enhanced synergistic response compared with high doses of treatment with individual compounds. Interestingly, this effect was observed using lower doses of the anticancer agent in combination with tocotrienols, suggesting that the toxicity factor related to these drugs may be avoided. The recent clinical trial, even though is reported as a null study, displayed promising reduction in the risk and recurrence free survival in women with early breast cancer. Nevertheless, tocotrienols exhibit potential as anticancer agents to be used in combination treatment as well as to enhance therapeutic responsiveness in breast cancer patients [99].

\section{Anti-inflammatory activity}

Tocotrienols have been extensively studied for their anti-inflammatory property and very promising scientific evidences have been brought up. The activation of the transcription factor NF- $\mathrm{kB}$ has been closely linked with inflammation $[101,102]$. Tocotrienols have been shown to suppress the expression of TNF- $\alpha$ [101,103], IL-1 [104], IL-6 [105], IL-8 [106], inducible nitric oxide synthase [107], and cyclo-oxygenase 2 [41,103], all of which mediate inflammation. Tocotrienols have also been shown to suppress STAT3 cell-signaling pathway, also involved in inflammation [71,85]. Hypoxia-induced factor-1 is another pathway that has been linked with inflammation and is modulated by tocotrienols [106]. Treatment of streptozotocin-induced diabetic rats with tocotrienols $(25 \mathrm{mg} / \mathrm{kg}$, $50 \mathrm{mg} / \mathrm{kg}$ and $100 \mathrm{mg} / \mathrm{kg}$ body weight) for 10 weeks, significantly prevented behavioral, biochemical and molecular changes associated with diabetes through suppression of activation of the NF- $\mathrm{kB}$ signaling pathway [103]. Nontoxic concentrations of tocotrienol attenuated the tumour necrosis factor- $\alpha$ (TNF)-induced nuclear transcription factor $(\mathrm{NF}-\mathrm{kB})$ activation in human chronic myeloid leukemia cells (KBM-5), which are the key steps in the development of inflammation [101].

\section{Anti-oxidant activity}

It is now well established that generation of free radicals $\left(\mathrm{O}_{2}^{-}, \mathrm{H}_{2} \mathrm{O}_{2}\right.$ and $\left.\mathrm{OH}^{-}\right)$from the incomplete reduction of molecular oxygen during aerobic respiration is closely related to cellular damage. Regulation of the balance between production of reactive oxygen species (ROS) by cellular processes and its removal by antioxidant defense system maintains normal physiological processes. The antioxidant activities of tocotrienols are mediated through induction of antioxidant enzymes such as superoxide dismutase [108,109], NADPH: quinoneoxidoreductase [110], and glutathione peroxidase [111], which quench free radicals such as superoxide radicals [112]. Effects of tocotrienols on antioxidant defense system in various animal models have been studied from time to time. Intragastric administration of tocotrienol for 30 days caused a significant elevation in different components of hepatic antioxidant defence and reduction in serum enzymes of hepatic damage in rats fed with 2-acetylaminofluorene (AAF) [113]. Shamaan et al. [114] investigated the effect of tocotrienol on the activities of glutathione S-transferases (GSTs), glutathione reductase (GR) and glutathione peroxidase $(\mathrm{GPx})$ in rats given 2-acetylaminofluorene (AAF) over a 20 week period. Liver and kidney GST and liver GR activities were significantly increased after AAF administration. Kidney GPx activities were significantly affected. In another experiment, alpha-tocopherol $(\alpha \mathrm{T})$ and gammatocotrienol $(\gamma \mathrm{T})$ were supplemented continuously for 8 weeks in the diets of normal rats and rats chemically induced with cancer using diethylnitrosamine (DEN), 2-acetylaminofluorene (AAF) and partial hepatectomy. Hepatocarcinogenesis was followed by determining the plasma gamma-glutamyl-transpeptidase (GGT) and alkaline phosphatase (ALP) activities as well as placental glutathione S-transferase (PGST) and GGT activities 
histochemically, at 4-week intervals. Male rats (Rattus norvegicus) were supplemented $\alpha \mathrm{T}$ and $\gamma \mathrm{T}$ at two different doses of 30 and $300 \mathrm{mg} / \mathrm{kg}$ diet. Elevation of plasma GGT activities and formation of PGST and GGT positive foci were attenuated significantly $(\mathrm{P}<0.05)$ when $\alpha \mathrm{T}$ and $\gamma \mathrm{T}$ were supplemented simultaneously with cancer induction [115]. Ong et al. [116] investigated the effect of tocotrienol and tocopherol on glutathione S-transferase (GST) and gamma-glutamyltranspeptidase (GGT) activities in cultured rat hepatocytes. Tocotrienol and tocopherol significantly decreased GGT activities at 5 days in culture but tocotrienol also significantly decreased GGT activities at 1-2 days. Tocotrienol and tocopherol treatment significantly decreased GST activities at 3 days compared to the control but tocotrienol also decreased GST activities at 1-3 days. Tocotrienol showed a more pronounced effect at a dosage of greater than 50 microM tocotrienol at 1-3 days in culture compared to the control.

Another group of researchers investigated the effects of tocotrienol-rich fraction (TRF) on exercise endurance and oxidative stress in forced swimming rats. The results showed that the TRF-treated animals $(268.0 \pm 24.1 \mathrm{~min}$ for TRF-25 and $332.5 \pm 24.3 \mathrm{~min}$ for TRF-50) swam significantly longer than the control $(135.5 \pm 32.9 \mathrm{~min})$ and T-25-treated (154.1 $\pm 36.4 \mathrm{~min})$ animals, whereas there was no difference in the performance between the T-25 and control groups [116]. The TRF-treated rats also showed significantly higher concentrations superoxide dismutase (SOD), catalase (CAT), and glutathione peroxidase (GPx), but lower levels in blood lactate, plasma and liver TBARS, and liver and muscle protein carbonyl. Their results suggested that TRF was able to improve the physiological condition and reduce the exercise-induced oxidative stress in forced swimming rats $[117,118]$.

\section{Anti-diabetic activity}

For centuries, dietary antioxidants are well-known for the management of diabetes and some of them have been experimentally evaluated. However search for new anti-diabetic drugs continues. $\alpha$-Tocotrienol $(0.1 \mathrm{~g} / \mathrm{kg})$ significantly prevented oxidative damage in streptozotocin (STZ)-induced diabetic Osteogenic Disorder Shionogi (ODS) rat [119]. The TRF at a dose of $1 \mathrm{~g} / \mathrm{kg}$ bodyweight significantly reduced streptozotocin induced diabetes in Sprague-Dawley rats [120]. It also effectively prevented increase in serum advanced glycosylation end-products (AGE) and malondialdehyde (MDA), and caused decrease in blood glucose and glycatedhemoglobin in diabetic rats. Intragastric administration of TRF from palm oil $(200 \mathrm{mg} / \mathrm{kg}$ ) significantly reduced the blood glucose level, oxidative stress markers and improved dyslipidemia in diabetic rats [121]. Diabetes is associated with a number of secondary complications such as neuropathy, retinopathy, nephropathy, lower limb amputations, etc. Kuhad et al.
[122] evaluated the impact of tocotrienol on cognitive function and neuroinflammatory cascade in streptozotocininduced diabetes. Streptozotocin-induced diabetic rats were treated with tocotrienol for 10 weeks. After 10 weeks of streptozotocin injection, the rats produced significant increase in transfer latency which was coupled with enhanced acetylcholinesterase activity, increased oxidative-nitrosative stress, TNF-alpha, IL-1beta, caspase- 3 activity and active p65 subunit of NF- $\mathrm{kB}$ in different regions of diabetic rat brain. Co-administration of tocotrienol significantly prevented behavioural, biochemical and molecular changes associated with diabetes. Moreover, diabetic rats treated with insulin-tocotrienol combination produced more pronounced effect on molecular parameters as compared to their per se groups. Tocotrienol also prevented diabetic neuropathy in rat models $[123,124]$. Oral administration of tocotrienol also significantly reduced the fasting serum glucose level in STZ induced diabetic rats by increased glucose metabolism and partly by hypotriglyceridemic effect of the plant extract. The extract also possessed oxidative stress reducing property in diabetic rats, which is believed to be a pathogenic factor in the development of diabetic complications [102,123,125-127]. The TRF from palm oil and rice bran oil was able to cause a significant reduction of elevated glucose-insulin index, signifying a potential insulin sensitizing effect in streptozotocin induced diabetic rats [127]. Oral administration of tocotrienol decreased the HbA1c, plasma glucose, lipids, peroxylipid (malonedialdehyde, MDA), albuminuria, proteinemia and uremia, and also improved the insulin sensitivity in various animal models [128-130]. It also prevents the incidence of long term complication in diabetic nephropathy $[103,119,126,127]$.

\section{Antihyperlipidemic activity}

Hyperlipidaemia is a group of disorders in which a person has increased levels of lipids in the bloodstream. These lipids consist of cholesterol, phospholipids, triglycerides and cholestryl esters. Since lipids are insoluble in aqueous medium, they are usually carried in body fluids as soluble protein complexes called as lipoproteins. Hyperlipidaemia can lead to a number of metabolic diseases like cardiovascular dysfunction and atherosclerosis. Hyperlipidemia may also result from diseases such as diabetes, thyroid disease, renal disorders, obesity, alcohol consumption and liver disorders. Oxidative stress is regarded as an important risk factor for hyperlipidemia. Tocotrienols, because of their antioxidant activity, have long been used for reducing blood lipid levels. Tocotrienols from barley, oats, palm and rice bran have been demonstrated to lower cholesterol levels in animals and humans [59,131-139], and that this effect has been reported to be mediated by suppressing HMG-CoA reductase activity through a post-translational mechanism [12,134]. Magosso et al. [140] conducted a first 
clinical trial that demonstrated mixed palm tocotrienols exhibited significant hepatoprotective effects in hypercholesterolemic adults with non-alcoholic fatty liver disease, and this effect was proposed to be mediated by attenuating triglyceride accumulation via regulation of fatty acid synthase and carnitine palmitoyl transferase leading to a reduction of hepatic inflammation and ER stress [141,142]. Furthermore, the study showed that tocotrienols significantly reduced serum levels of total cholesterol (TC), low density lipoproteins (LDL) and triglycerides (TG) compared to baseline. In patients with hyperlipidemia and carotid stenosis, long term treatment with palm oil (a rich source of tocotrienols) resulted in attenuation of oxidative modification of LDL and significantly prevented the initiation and propagation of atherosclerosis [143]. In two open clinical studies, tocotrienol (75 mg/day) supplementation for 2 months significantly reduced fasting blood lipid levels. TC levels dropped 13\% and LDL-C dropped 9-15\%, whereas high density lipoprotein-cholesterol (HDL-C) increased by 4-7\%. In addition, $\delta$-tocotrienol promoted metabolic health, where TG levels dropped $20-30 \%$ [144].

\section{Immunomodulatory activity}

Tocotrienol's virtues as an immune enhancer are only beginning to receive recognition in medicine. Tocotrienol enhanced both antigen specific (observed against humoral as well as Cell-mediated immune response) and nonspecific responses. Tocotrienols have been shown to induce favourable effects on the human immune system. A team of Malaysian scientists evaluated the effects of a tocotrienol compound on immune function, recruiting 108 healthy non-smoking women, ages 18 and 25 years, for a two-month long study. One group received $400 \mathrm{mg}$ of tocotrienol compound per day, while the other group received placebo (400 $\mathrm{mg} /$ day soy oil) for the study period. Blood samples were analyzed at the start of the study, and again after 28 and 56 days. After 28 days of supplementation, all subjects received a single shot of tetanus toxoid (TT) vaccine. The team observed significant increases in levels of the anti-TT antibody, interferon (IFN)-gamma and interleukin (IL)-4 in the tocotrienol group, as compared with the placebo group. The researchers concluded that tocotrienols have immunostimulatory effects and potential clinical benefits to enhance immune response [145]. A study was conducted to determine the effect of dietary supplementation of tocotrienols on immune response of young and old C57BL/6 mice using a wide range of immune indices. The study demonstrated that dietary supplementation with T3 resulted in enhanced $\mathrm{T}$ cell proliferation [146]. In another study, the immunoregulatory effects of dietary $\alpha$-tocopherol (Toc) and tocotrienols (T3) on humoral and cell-mediated immunity and cytokine productions were examined in
Brown Norway rats. It was found that the IgA and IgG productivity of spleen and mesenteric lymph node (MLN) lymphocytes was significantly enhanced in the rats fed on Toc or T3, irrespective of concanavalin A (Con A) stimulation of the lymphocytes. On the contrary, the IgE productivity of lymphocytes from the rats fed on Toc or T-3 was less without ConA stimulation, but was greater in the presence of Con A, especially in the T3 group. Toc or T3 feeding significantly decreased the proportion of $\mathrm{CD}^{+} \mathrm{T}$ cells and the ratio of $\mathrm{CD} 4^{+} / \mathrm{CD}^{+}$in both spleen and MLN lymphocytes of the rats fed on Toc or T3. The interferon$\gamma$ productivity of MLN lymphocytes was higher in the rats fed on Toc or T3 than in those fed on a control diet in the presence of Con A, while that of spleen lymphocytes was lower in the rats fed on Toc or T3. In addition, T3 feeding decreased the productivity of tumor necrosis factor- $\alpha$ of spleen lymphocytes, while it enhanced the productivity of MLN lymphocytes. The results suggested that oral administration of Toc and T3 affected the proliferation and function of spleen and MLN lymphocytes [147]. The TRF was found to enhance immune response to tetanus toxoid (TT) immunisation in BALB/c mice. The production of anti-TT antibodies was augmented $(\mathrm{P}<0.05)$ in mice that were fed with $\delta$-T3 or TRF. The production of IFN- $\gamma$ and IL-4 by splenocytes from the TRF treated mice was significantly $(\mathrm{P}<0.05)$ higher. Production of TNF- $\alpha$ was also suppressed in the vitamin E supplemented mice [148]. All these findings suggest that tocotrienol could be a useful "natural complement" for immune boasting.

\section{Protection against cardiovascular disease}

Cardiovascular disorder is the one of the most potent causes of death throughout the world and the role of tocotrienols in its prevention may have significant clinical implications. Out of a minimum of four different isoforms of tocotrienols, a- and c-tocotrienols are considered as the effective isoforms which possess the cardioprotective abilities. A number of studies have determined the cardioprotective abilities of tocotrienols and have been shown to possess novel hypocholesterolemic effects together with an ability to reduce the atherogenic apolipoprotein and lipoprotein plasma levels. In addition, tocotrienol has been suggested to have an antioxidant, anti-thrombotic, and antitumor effect indicating that tocotrienol may serve as an effective agent in the prevention and/or treatment of cardiovascular disease and cancer. The bioactivity exhibited is due to the structural characteristics of tocotrienols. Rich sources of tocotrienols which include rice bran, palm oil, and other edible oils exhibit protective effect against cardiovascular disorders [149].

Diseases that involve the heart and blood vessels remain the biggest cause of deaths worldwide. Coronary heart disease, cardiomyopathy, ischemic heart disease, heart failure, hypertensive heart disease, inflammatory 
heart disease and valvular heart disease are some of cardiovascular complications. Tocotrienol has long been used for various cardiac complications. Tocotrienols' cardioprotective effects are mediated through their antioxidant mechanisms and their ability to suppress inflammation, and inhibit HMG-CoA reductase, a rate-limiting enzyme in cholesterol biosynthesis $[11,12,150]$, and reduce the expression of adhesion molecules and monocyteendothelial cell adhesion [151]. Tocotrienols were found to be more effective than $\alpha$-tocopherol in depressing agerelated increases in systolic blood pressure of spontaneously hypertensive rats [152]. TRF from rice bran oil improved lipid abnormalities, reduced the atherogenic index and suppressed the hyperinsulinemic response in rats with streptozotocin/nicotinamide-induced type 2 diabetes mellitus [153]. Tocotrienol significantly alleviated atherosclerotic iliac artery stenosis induced by both the endothelialization and high cholesterol diet. It also significantly lowered aortic contents of malondialdehyde and intimal thickening as well as preserved the internal elastic lamina in rabbits [154]. The tocotrienols also significantly alleviated the ischemia-reperfusion injury, and reduced infarct size in the ischemic region of myocardial tissue, through the downmodulation of $\mathrm{c}$-Src and upregulation of phosphorylation of Akt, thus generating a survival signal [155]. Treatment of tocotrienols orally to pigs expressing hereditary hypercholesterolemia significantly reduced serum total cholesterol, LDL-cholesterol, apolipoprotein $\mathrm{B}$, platelet factor 4 , thromboxane $\mathrm{B}(2)$, glucose, triglycerides, and glucagon. The tocotrienols also lowered the hepatic HMG-CoA reductase activity and cholesterol and fatty acid levels in various tissues [156].

In one study, the effects of red palm oil on the myocardial nitric oxide-cGMP signaling pathway, associated with myocardial protection against ischemia, were investigated [157]. Treatment with red palm oil increased aortic output and increased levels of cGMP and polyunsaturated fatty acid in rat hearts suggesting that dietary red palm oil protects via the nitric oxide-cGMP pathway and/or changes in polyunsaturated fatty acid composition during ischemia/reperfusion. Newaz et al. [109] determined the effects of $\gamma$-tocotrienol on lipid peroxidation and total antioxidant status of spontaneously hypertensive rats. The $\gamma$-tocotrienol exhibited a dose dependent hypotensive effect on the systolic blood pressure of spontaneously hypersensitive rats. It also caused a significant drop in the mean arterial pressure in a dose dependent manner, decreased lipid peroxidation and increased the activity of antioxidant enzymes in hearts of rats. Myocardial ischemic injury results from severe impairment of coronary blood supply and produces a spectrum of clinical syndromes. In a study, $\gamma$-tocotrienol significantly reduced coronary perfusion pressure and heart rate. It exerted protection against myocardial injury by mitigating cardiac dysfunction and oxidative injury in rats and also by the differential interaction of MAPK with caveolin $1 / 3$ in conjunction with proteasome stabilization, possibly by altering the availability of prosurvival and antisurvival proteins [158]. Diabetes mellitus is always accompanied by dyslipidemia, which is an important factor in the pathogenesis of diabetic complications, such as cardiovascular diseases and diabetic nephropathy. The TRF from palm oil and rice bran oil has been shown to decrease the serum lipid profile in type-1 and type-2 diabetic Wistar rats $[127,130]$. It has also been reported to decrease the dyslipidemia induced diabetic nephropathy through the downregulation of the TGF- $\beta$ expression [127].

\section{Neuroprotective effects}

Various reports suggest that tocotrienols are neuroprotective [159-166]. Tocotrienols also have activity against Parkinson disease [167]. In one study, HT4 hippocampal neuronal cells were studied to compare the efficacy of tocopherols and tocotrienol to protect against glutamateinduced death. Tocotrienols were more effective than alpha-tocopherol in preventing glutamate-induced death. It was suggested that tocotrienols may have protected cells by an antioxidant-independent mechanism. Examination of signal transduction pathways revealed that protein tyrosine phosphorylation processes played a central role in the execution of death. Activation of pp60(c-Src) kinase and phosphorylation of ERK were observed in response to glutamate treatment. Nanomolar amounts of $\alpha$-tocotrienol, but not $\alpha$-tocopherol, blocked glutamate-induced death by suppressing glutamate-induced early activation of c-Src kinase. Overexpression of kinase-active c-Src sensitized cells to glutamate-induced death. Tocotrienol treatment prevented death of Src-overexpressing cells treated with glutamate [159].

A growing body of research supports that members of the vitamin E family are not redundant with respect to their biological function. Palm oil derived from Elaeis guineensis represents the richest source of the lesser characterized vitamin $\mathrm{E}, \alpha$-tocotrienol. One of 8 naturally occurring and chemically distinct vitamin $\mathrm{E}$ analogs, $\alpha$-tocotrienol possesses unique biological activity that is independent of its potent antioxidant capacity. Current developments in $\alpha$-tocotrienol research demonstrate neuroprotective properties for the lipid-soluble vitamin in brain tissue rich in polyunsaturated fatty acids (PUFAs). Arachidonic acid (AA), one of the most abundant PUFAs of the central nervous system, is highly susceptible to oxidative metabolism under pathologic conditions. Cleaved from the membrane phospholipid bilayer by cytosolic phospholipase A2, AA is metabolized by both enzymatic and nonenzymatic pathways. A number of neurodegenerative conditions in the human brain are associated with disturbed PUFA metabolism of AA, including acute 
ischemic stroke. Palm oil-derived $\alpha$-tocotrienol at nanomolar concentrations has been shown to attenuate both enzymatic and nonenzymatic mediators of AA metabolism and neurodegeneration. On a concentration basis, this represents the most potent of all biological functions exhibited by any natural vitamin E molecule. Despite such therapeutic potential, the scientific literature on tocotrienols accounts for roughly $1 \%$ of the total literature on vitamin E, thus warranting further investigation [168].

A growing body of literature has begun to delineate the unique and potent biological properties of the natural vitamin E, $\alpha$ TCT [169]. To date, the neuroprotective qualities of $\alpha \mathrm{TCT}$ in neurodegenerative disorders of the CNS are well characterized, with specific molecular targets (cPLA2, 12-LOX, and c-Src) and mechanisms of action identified. Beyond the CNS, $\alpha$ TCT has also demonstrated therapeutic promise in the treatment cancer and hypercholesterolemia. As a dietary source in humans, the oil palm represents the richest source of $\alpha \mathrm{TCT}$ known today. Although tocotrienols are present in edible products such as palm oil, it remains questionable whether a dietary source alone could provide sufficient amounts of $\alpha$ TCT to humans [169], which is particularly relevant in diets that are typically devoid of palm oil and other natural sources of $\alpha$ TCT. Enrichment of $\alpha$ TCT from crude palm oil for dietary supplementation is achievable, and to date represents the most cost effective and readily available source of natural $\alpha$ TCT [168].

a-Tocotrienol (TCT) represents the most potent neuroprotective form of natural vitamin $\mathrm{E}$ that is generally recognized as a safe certified by the U.S. Food and Drug Administration. The recent work of Park et al. [170] addresses a novel molecular mechanism by which a-TCT may be protective against stroke in vivo. Elevation of intracellular oxidized glutathione (GSSG) triggers neural cell death. Multidrug resistance-associated protein 1 (MRP1), a key mediator of intracellular oxidized glutathione efflux from neural cells, may therefore possess neuroprotective functions. Stroke-dependent brain tissue damage was studied in MRP1-deficient mice and a-TCT-supplemented mice. Elevated MRP1 expression was observed in glutamate-challenged primary cortical neuronal cells and in stroke-affected brain tissue. MRP1-deficient mice displayed larger stroke-induced lesions, recognizing a protective role of MRP1. In vitro, protection against glutamate-induced neurotoxicity by a-TCT was attenuated under conditions of MRP1 knockdown; this suggests the role of MRP1 in a-TCT-dependent neuroprotection. In vivo studies demonstrated that oral supplementation of a-TCT protected against murine stroke. MRP1 expression was elevated in the stroke-affected cortical tissue of a-TCT-supplemented mice. Efforts to elucidate the underlying mechanism identified MRP1 as a target of a microRNA (miRNA). In a-TCT-supplemented mice, the
miRNA was downregulated in stroke-affected brain tissue [170]. The work of Park et al. [170] recognizes MRP1 as a protective factor against stroke. Furthermore, findings of this study add a new dimension to the current understanding of the molecular bases of a-TCT neuroprotection in 2 ways: by identifying MRP1 as a a-TCT-sensitive target and by unveiling the general prospect that oral a-TCT may regulate miRNA expression in stroke-affected brain tissue [170]. Hence, the findings of their study add a new dimension to the current understanding of the molecular bases of a-TCT neuroprotection in 2 ways: by identifying MRP1 as a-TCT-sensitive target and by unveiling the general prospect that oral a-TCT may regulate microRNA expression in stroke-affected brain tissue. Neuroprotective, as well as hypocholesterolemic, properties of a-TCT make it a good candidate for nutrition based intervention in people at high risk for stroke. Transient ischemic attack, or mini-stroke, serves as a sentinel warning sign for highrisk stroke patients. Prophylactic stroke therapy therefore provides an opportunity for intervention in patients transient ischemic attack before a major stroke event. Outcomes of the current study warrant clinical assessment of a-TCT in transient ischemic attack patients. Furthermore, a-TCT is a nutrient that is certified by the U.S. Food and Drug Administration to be generally recognized as safe and is not a drug with potential side effects. Thus, a-TCT may be considered as a preventive nutritional countermeasure for people at high risk for stroke.

In order to determine whether the neuroprotective activity of alpha-tocotrienol is antioxidant-independent or -dependent, Khanna et al. [162] conducted a study using two different triggers of neurotoxicity, homocysteic acid (HCA) and linoleic acid. Both HCA and linoleic acid caused neurotoxicity with comparable features, such as increased ratio of oxidized to reduced glutathione GSSG/GSH, raised intracellular calcium concentration and compromised mitochondrial membrane potential. Mechanisms underlying HCA-induced neurodegeneration were comparable to those in the path implicated in glutamateinduced neurotoxicity. Inducible activation of $\mathrm{c}-\mathrm{Src}$ and 12-lipoxygenase (12-Lox) represented early events in that pathway. Overexpression of active $\mathrm{c}$-Src or 12Lox sensitized cells to HCA-induced death. Nanomolar $\alpha$-tocotrienol was protective. Knock-down of c-Src or 12-Lox attenuated HCA-induced neurotoxicity. Oxidative stress represented a late event in HCA-induced death. The observation that micromolar, but not nanomolar, $\alpha$-tocotrienol functions as an antioxidant was verified in a model involving linoleic acid-induced oxidative stress and cell death. Oral supplementation of alpha-tocotrienol to humans results in a peak plasma concentration of $3 \mathrm{mM}$. Thus, oral $\alpha$-tocotrienol may be neuroprotective by antioxidant-independent as well as antioxidant-dependent mechanisms [162]. In another study, Khanna et al. [164] 
tested the hypothesis that phospholipase A2 (PLA2) activity is sensitive to glutamate and mobilizes arachidonic acid (AA), a substrate for 12-lipoxygenase. Furthermore, the researchers examined whether $\alpha$-tocotrienol (TCT) regulates glutamate-inducible PLA2 activity in neural cells. Glutamate challenge induced the release of $\left[{ }^{3} \mathrm{H}\right] \mathrm{AA}$ from HT4 neural cells. Such response was attenuated by calcium chelators, ethylene glycol tetraacetic acid (EGTA) and 1,2-bis(o-aminophenoxy)ethane- N,N,N',N'-tetraacetic acid (BAPTA), cytosolic PLA2 (cPLA2)-specific inhibitor arachidonyltrifluoromethyl ketone (AACOCF3) as well as TCT at $250 \mathrm{nM}$. Glutamate also caused the elevation of free polyunsaturated fatty acid (AA and docosahexaenoic acid) levels and disappearance of phospholipid-esterified AA in neural cells. Furthermore, glutamate induced a time-dependent translocation and enhanced serine phosphorylation of cPLA2 in the cells. These effects of glutamate on fatty acid levels and on cPLA2 were significantly attenuated by TCT. The observations that AACOCF3, transient knock-down of cPLA2 as well as TCT significantly protected against the glutamate-induced death of neural cells implicate cPLA2 as a TCT-sensitive mediator of glutamate induced neural cell death. The study suggested that TCT provided neuroprotection through glutamateinduced changes in cPLA2. Tocotrienols have also been found to possess neuroprotective activity in animal models of diabetic neuropathy $[103,122,124,170]$ and alcoholic neuropathy $[171,172]$. Tocotrienols have been reported to suppress the proinflammatory pathways in diabetes and chronic alcoholism, which in turn prevented the animals from cognitive impairment and oxidative-nitrosative stress.

\section{Positive effects on bone metabolism}

Bone is a specialised connective tissue hardened by mineralisation with calcium phosphate in the form hydroxyapatite $\left(\left[\mathrm{Ca}_{3}\left(\mathrm{PO}_{4}\right)_{2}\right] \mathrm{Ca}(\mathrm{OH})_{2}\right)$. Bone has well recognised mechanical functions: it provides rigidity and shape, protection and support for body structures, and aids locomotion. The rate of bone turnover, collagen matrix, size, structure, geometry and density all combine to determine the bone's overall mechanical properties. Defects in these parameters will result in diseases such as osteoporosis, Paget's disease of bone, osteoporosis and osteogenesis imperfecta. In order for the strength of the bone to be maintained, the process of bone turnover must be carefully regulated. Vitamin $\mathrm{E}$ and its various forms have been reported to help in the maintenance of bone metabolism [104,105,173-182]. Vitamin E supplements reversed nicotine-induced bone loss and stimulated bone formation $[173,174]$. Tocotrienols are slightly superior to tocopherols in attenuating the effects of tobacco; $\gamma$-tocotrienol especially may have therapeutic potential to repair bone damage caused by chronic smoking. Other studies have shown that tocotrienols can reverse glucocorticoid-induced or free radical-induced bone loss in adrenalectomized rats $[105,175,177]$ and improve normal bone structure $[175,177,178]$ possibly through its antioxidant activity in bone $[177,182]$. Ima-Nirwana et al. [180] showed that treatment with $\gamma$-tocotrienol $(60 \mathrm{mg} / \mathrm{kg}$ body weight/day) reduced body fat mass and increased fourth lumbar vertebra bone calcium content in rats, while a-tocopherol was ineffective. Therefore, palm-oil derived $\gamma$-tocotrienol has the potential to be utilized as a prophylactic agent in prevention of the skeletal side effects of long-term glucocorticoid and tobacco use (Figure 1).

\section{Gastroprotective effects}

Azlina et al. compared the impacts of tocopherols and tocotrienols on gastric acidity, gastric tissue content of parameters such as malondialdehyde and prostaglandin E2, and serum levels of gastrin and glucagon-like peptide-1 in rats exposed to restraint stress. They found that tocotrienol-treated animals, both stressed and non-stressed, had comparable gastric acidity and gastrin levels [183]. Both tocopherols and tocotrienols had gastroprotective effects against damage by free radicals generated in stress conditions, but only tocotrienols had the ability to block stress induced changes in gastric acidity and gastrin level. Another group showed that tocotrienols can prevent aspirin-induced gastric lesions through their ability to limit lipid peroxidation [184].

\section{Hepatoprotective activity}

Liver the largest glandular organ of the body and the key organ of metabolism has a pivotal and immense task of detoxification of xenobiotics, environmental pollutants and chemotherapeutic agents. Hence this organ is subjected to a variety of diseases and disorders. In the absence of reliable hepatoprotective drugs in the allopathic (modern) medicinal system and the wide range of hepatic disorders, dietary antioxidants play an important role in the management of liver disorders.

Tocotrienol has been extensively studied for its efficacy against hepatic toxicity. Oral administration of tocotrienols offered a significant protection against 2-acetylaminofluorene (AAF) induced hepatotoxicity as assessed in terms of biochemical and histological parameters [113,114]. Tocotrienols completely normalized the 2-acetylaminofluorene (AAF) induced increase in the levels of plasma and liver microsomal gamma-glutamyltranspeptidase (GGT) and liver microsomal UDP-glucuronyltransferase (UDP-GT) confirming in vivohepatoprotective activity of tocotrienols against AAF induced toxicity. Tocopherol and $\gamma$-tocotrienol have been shown to prevent the nitrofurantoin induced damage in rat liver when administered for 10 weeks. The extract characteristically inhibited hepatic lipid peroxidation [111]. Tocotrienol also significantly 


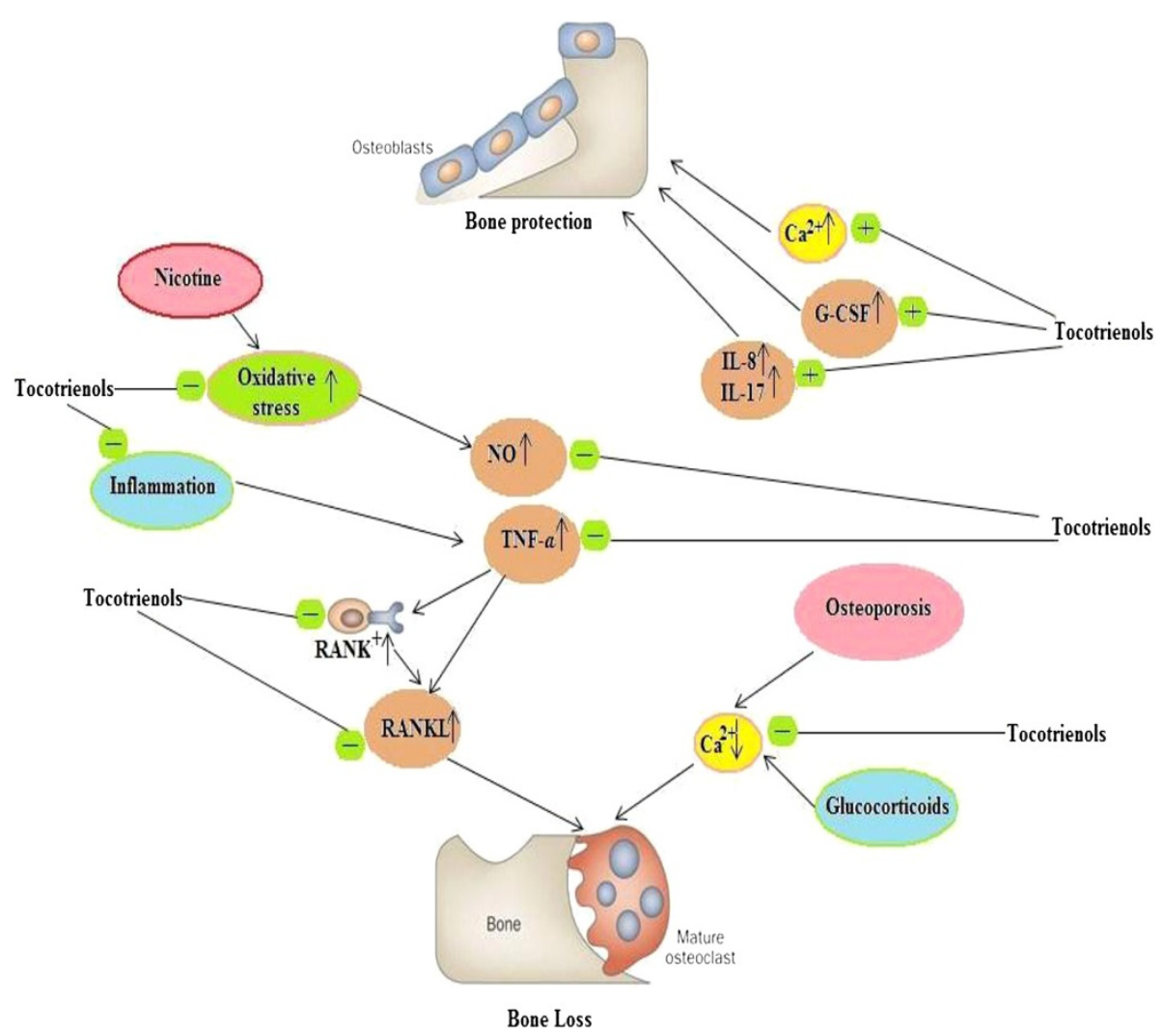

Figure 1 Mechanistic action of tocotrienols in bone protection. Tocotrienols prevent the increase in expression of TNF- $a$ and nitric oxide (NO) due to nicotine administration, oxidative stress and inflammation and thus prevent osteoclast formation. Tocotrienols also downregulate the expression of Receptor activator of nuclear factor kappa-B (RANK) and Receptor activator of nuclear factor kappa-B ligand (RANKL). Osteoporosis and glucocorticoids also decrease the calcium ion concentration in bone leading to bone desorption. Tocotrienols prevent the desorption of calcium ions from bone, thus increasing the bone strength. Tocotrienols also increase the expression of interleukin-8 (IL-8), IL-17, granulocyte colony stimulating factor (G-CSF) which in turn lead to the formation of bone osteoblasts.

increased the percent viability of cultured rat hepatocytes prepared from rats treated with diethylnitrosamine (DEN) and 2-acetylaminofluorene (AAF). Tocotrienol significantly decreased levels of glutathione S-transferase (GST) and gamma-glutamyltranspeptidase (GGT) activities in cultured rat hepatocytes at 1-3 days [116,185]. In addition to their antioxidant activity, tocotrienols are found to increase the expression of drug metabolising enzymes such as cytochrome P450 enzyme (CYP450), UDP-glucuronosyltransferase 1A1 (UGT1A1) and multidrug resistance protein-1 (MDR1) via the activation of the pregnane-Xreceptor (PXR) and steroid and xenobiotic receptor (SXR), which are the nuclear receptors that regulate drug clearance in the liver and intestine via induction of genes involved in drug and xenobiotic metabolism, thus increasing the activity of liver to metabolize the xenobiotics $[186,187]$. Oral administration of TRF on exercise endurance and oxidative stress in forced swimming rats caused significant increase in the concentrations of liver glycogen, SOD, CAT, and GPx, as well as of muscle glycogen and SOD than the control and lowered levels of blood lactate, plasma and liver TBARS, and liver and muscle protein carbonyl. Taken together, these results suggest that TRF is able to improve the physiological condition and reduce the exercise-induced oxidative stress in forced swimming rats [108].

Organophosphorus insecticides (OPIs) may induce oxidative stress leading to generation of free radicals and alteration in antioxidant system of animals. Bhatti et al. $[188,189]$ conducted a study to investigate the possible protective role of vitamin $\mathrm{E}$ on ethion-induced hepatotoxicity in rats using qualitative, quantitative and biochemical approaches. The result of their study shows that in vivo administration of ethion caused a significant induction of oxidative damage in liver tissue as evidenced by increased level of LPO and decreased GSH content. Ethion toxicity also led to a significant increase in the activities of SOD, CAT, GPx and GST in liver tissue. In addition, decrease in GR activity was observed in ethion administered rats compared to control. Histopathological findings revealed that exposure to ethion caused damage in liver tissue. However, simultaneous supplementation with 
vitamin $\mathrm{E}$ restored these parameters partially. The results revealed that supplementation of vitamin $\mathrm{E}$ exhibited protective effect by inhibiting ethion-induced toxicity in liver and erythrocytes. Patel et al. [190] conducted a study to determine the concentrations of TE (200 mg mixed TE, b.i. d.) and TCP (200 mg alpha-TCP, b.i.d.) in vital tissues and organs of adults receiving oral supplementation. A total of eighty participants were studied. Skin and blood vitamin E concentrations were determined from healthy participants following $12 \mathrm{wk}$ of oral supplementation of TE or TCP. Vital organ vitamin E levels were determined by HPLC in adipose, brain, cardiac muscle, and liver of surgical patients following oral TE or TCP supplementation (mean duration, $20 \mathrm{wk}$; range, 1-96 wk). Oral supplementation of TE significantly increased the TE tissue concentrations in blood, skin, adipose, brain, cardiac muscle, and liver over time. The alpha-TE was delivered to human brain at a concentration reported to be neuroprotective in experimental models of stroke. In prospective liver transplantation patients, oral TE lowered the model for end-stage liver disease (MELD) score in 50\% of patients supplemented, whereas only $20 \%$ of TCP-supplemented patients demonstrated a reduction in MELD score. The results demonstrated that orally supplemented TE are transported to vital organs of adult humans. The findings of this study, in the context of the current literature, lay the foundation for Phase II clinical trials testing the efficacy of TE against stroke and end-stage liver disease in humans. All these findings are very promising and demand the attention of the scientific community for further exploration and evaluation of tocotrienols against hepatic toxicity.

\section{Nephroprotective activity}

The kidneys are organs that serve several essential regulatory roles in vertebrate animals. They are essential in the urinary system and also serve homeostatic functions such as the regulation of electrolytes, maintenance of acid-base balance, and regulation of blood pressure (via maintaining salt and water balance). They serve the body as a natural filter of the blood, and remove wastes produced by metabolism in the form of urine. Just like liver, kidneys are also susceptible to a variety of diseases and disorders. Tocotrienols have been reported to possess significant nephroprotective activity. In one study, the effects of a long-term treatment with vitamin $E$ ( $\alpha$-tocophenol), insulin, or their combination on renal damage in STZ-induced diabetic rats fed a high cholesterol diet was investigated. Increases in urinary albumin and lipid peroxide (LPO) excretions were observed in these diabetic rats, when both urinary parameters were measured at 8 and 15 weeks after STZ administration. Daily treatment with $\alpha$-tocophenol, insulin, or their combination markedly suppressed the increase in the $24 \mathrm{~h}$ urinary albumin and lipid peroxide excretions. Furthermore, glycogen degeneration of distal tubules, fatty degeneration of glomerular endothelium and hypertrophy of glomeruli and mesangium were observed in the kidneys of the diabetic animals when histopathological evaluation was performed at 4, 8, and 15 weeks (glomerular and mesangial hypertrophy were observed only at 15 weeks). Combined $\alpha$-tocophenol (vitamin E) and insulin treatment was the most effective at suppressing these renal histopathological changes. Hence, the results indicated that combined vitamin $\mathrm{E}$ and insulin treatment additively prevented the development and progression of renal damage in diabetic rats, possibly because of their antioxidant and hypolipidemic activity [191].

Tocotrienol $(100 \mathrm{mg} / \mathrm{kg})$ as well as TRF $(200 \mathrm{mg} / \mathrm{kg})$ from palm oil and rice bran oil prevents the kidneys from diabetic nephropathy in streptozotocin-induced type-1 and high-fat diet/streptozotocin induced type-2 diabetic rats. Diabetic rats produced significant alteration in renal function, increased oxidative-nitrosative stress, TNF-alpha, TGF-beta1, caspase-3 activity in cytoplasmic lysate and active p65 subunit of NF-kB in nuclear lysate of kidney of diabetic rats. Interestingly, administration of tocotrienol and TRF from rice bran oil and palm oil significantly and dose-dependently prevented biochemical and molecular changes associated with diabetes. Tocotrienols modulated the release of profibrotic cytokines, oxidative stress, ongoing chronic inflammation and apoptosis and thus exerts a marked renoprotective effect $[103,126,127]$.

Tocotrienol also prevents the kidneys from ferric nitrilotriacetate (Fe-NTA) toxicity, a well-established nephrotoxic agent. Pretreatment with tocotrienol $(50 \mathrm{mg} / \mathrm{kg} /$ day $)$ for 7 days before Fe-NTA administration in rats significantly reduced the serum creatinine and BUN levels, reduced lipid peroxidation in a significant manner, and restored levels of reduced glutathione and superoxide dismutase. Tocotrienol pretreatment also attenuated the serum tumor necrosis factor-alpha levels and restored normal renal morphology [192]. TRF from palm oil (200 mg/kg, bw, orally, once daily for 21 days) was also found to prevent the kidneys in rats from potassium dichromate and Fenitrothion (FNT) induced acute renal toxicity [193,194]. Nowak et al. [195] conducted a study to determine whether $\gamma$-tocotrienol $(\gamma \mathrm{T} 3)$ protects against mitochondrial dysfunction and renal proximal tubular cell (RPTC) injury caused by oxidants. Primary cultures of RPTCs were injured by using tert-butyl hydroperoxide (TBHP) in the absence and presence of $\gamma \mathrm{T} 3$ or AT. ROS production increased 300\% in TBHP-injured RPTCs. State 3 respiration, oligomycin-sensitive respiration, and respiratory control ratio (RCR) decreased 50, 63, and 47\%, respectively. The number of RPTCs with polarized mitochondria decreased 54\%. F(0)F(1)-ATPase activity and ATP content decreased 31 and 65\%, respectively. Cell lysis 
increased from $3 \%$ in controls to 26 and $52 \%$ at 4 and $24 \mathrm{~h}$, respectively, after TBHP exposure. $\gamma \mathrm{T} 3$ blocked ROS production, ameliorated decreases in state 3 and oligomycin-sensitive respirations and $\mathrm{F}(0) \mathrm{F}(1)$-ATPase activity, and maintained RCR and mitochondrial membrane potential (DeltaPsi(m)) in injured RPTCs. GT3 maintained ATP content, blocked RPTC lysis at $4 \mathrm{~h}$, and reduced it to $13 \%$ at $24 \mathrm{~h}$ after injury. Treatment with equivalent concentrations of AT did not block ROS production and cell lysis and moderately improved mitochondrial respiration and coupling. This is the first report demonstrating the protective effects of GT3 against RPTC injury by: i) decreasing production of ROS, ii) improving mitochondrial respiration, coupling, Delta-Psi $(\mathrm{m})$, and $\mathrm{F}(0) \mathrm{F}(1)$-ATPase function, iii) maintaining ATP levels, and iv) preventing RPTC lysis. The data suggested that GT3 is superior to AT in protecting RPTCs against oxidant injury and may prove therapeutically valuable for preventing renal injury associated with oxidative stress.

\section{Radioprotective effects}

Radiation-induced toxicity in various tissues is a manifestation of free radicals, oxidative stress, DNA damage [196], inflammation, [197] and apoptosis [198]. These different signaling pathways are known to have deleterious effects in various diseases such as hypertension, diabetes, and cancer progression [197,199]. Various compounds such as antioxidants, thiols, antiapoptotic molecules, cytokines and growth factors have been tested against acute radiation injury [200-202]. Ghosh et al. [203] have shown that the prophylactic treatment with gammatocotrienol (GT3), $24 \mathrm{~h}$ prior to irradiation protects mice from radiation injury. Radioprotection by GT3 is associated with reduction of radiation-induced DNA damage [204] and inhibition of HMGCR-mediatednitrosative stress [205]. GT3 is also shown to increase serum interleukin-6 (IL-6) and G-CSF levels which are known to stimulate hematopoiesis. Induction of these cytokines may contribute to radioprotective action of GT3 [206].

The radioprotective effect of GT3 depends not only on its antioxidative properties but also on its abilities to concentrate in endothelial cells and inhibit the enzyme, 3-hydroxy-3-methylglutaryl-coenzyme A (HMG-CoA) reductase. HMG-CoA reductase inhibitors are commonly used in the treatment of hyperlipidemia disorders but in addition have a plethora of vasculoprotective, antiinflammatory and anti-fibrotic effects mediated by endothelial nitric oxide synthase (eNOS, NOS3) [207,208].

In an attempt to enhance the radioprotective efficacy of GT3, Kulkarni et al. [209] tested the effect of PTX, a methyl derivative of xanthine, in combination with GT3. They have shown that the increase in the radioprotective efficacy of GT3 by combining it with pentoxifylline
(PTX) was due to PDE inhibition, an effect that was reversed by calmodulin administration [209]. PTX has similar antioxidant, vasculoprotective, anti-inflammatory and anti-fibrotic properties and similarly increases eNOS activity through an increase in intracellular cyclic adenosine monophosphate (cAMP) [210-212].

PTX is an FDA-approved non-specific PDE inhibitor used for intermittent claudication $[213,214]$. PTX has been used alone and in combination with vitamin $\mathrm{E}$ (alphatocopherol) in preclinical and clinical studies to reduce long-term effects of radiation such as fibrosis [215-217]. Beneficial effects of PTX are contributed to its ability to inhibit proinflammatory cytokine signaling such as tumor necrosis factor-alpha (TNF- $\alpha$ ) accumulation [218]. According to these studies, there was significant reduction in TNF- $\alpha$ in presence of PTX in early ( 2 weeks) as well as late (24 weeks) phase of radiation injury. It was recently shown that combining PTX with GT3 increased the radioprotective efficacy of GT3 in protecting mice from acute radiation injury [218]. These studies indicated that even though PTX increased the radioprotection in mice treated with GT3, its mechanism of protection was independent of endothelial nitric oxide synthase (eNOS). PTX was shown to increase nitric oxide production [210] by increasing cAMP levels.

Berbee et al. [219] examined the effects of GT3 in combination with PTX on total body irradiation (TBI)induced acute hematopoietic, intestinal and vascular injury and subsequent mortality. They used eNOS-deficient mice to determine whether protection against lethality from either drug alone or the combination required the presence of eNOS. Combined therapy was significantly more effective in improving postirradiation survival than treatment with GT3 only, but the effect on postirradiation lethality did not require the presence of eNOS. Moreover, their data suggested that administration of GT3 together with PTX may modulate the hematopoietic radiation response by the induction of hematopoietic stimuli. GT3 combined with PTX also reduced postirradiation intestinal injury and vascular oxidative stress compared to vehicle, but no additional benefit was observed by the addition of PTX to GT3 compared to treatment with GT3 alone [219].

\section{Toxicity and dosage}

To start with, quoting Paracelsus (1493-1541 Switzerland), "in all things there is a poison, and there is nothing without a poison. It depends on only upon the dose whether a poison is a poison or not". Under dietary considerations, tocotrienol has been regarded as a safe biomolecule and experimental studies have also supported this view. There is no possible report of any adverse reactions caused by tocotrienol, except that in a study done on experimental animals in a 13-week oral toxicity study performed in 
Fischer 344 rats of both sexes at dose levels of 0\% (group 1), $0.19 \%$ (group 2), $0.75 \%$ (group 3) and 3\% (group 4) of a diet preparation in powdered form. On hematological examination, significant decrease in mean corpuscular volume $(\mathrm{MCV})$ was observed in all treated males. Platelets were significantly reduced in group 3 and 4 males. Hemoglobin concentration, MCV, mean corpuscular hemoglobin and mean corpuscular hemoglobin concentration were significantly decreased in group 3 and 4 females and hematocrit in group 4 females. On biochemical examination, increase in the albumin/globulin ratio $(\mathrm{A} / \mathrm{G})$ and alkaline phosphatase in all treated males, elevated alanine transaminase in group 4 of both sexes and increases in asparagine transaminase and gamma-glutamyl transaminase in group 4 females were observed. With regard to relative organ weights, liver weights in group 4 of both sexes and adrenal weights in all treated males demonstrated an increase, and ovary and uterus weights in group 4 females were reduced. A slight hepatocellular hypertrophy in group 3 and 4 males, and reduction of cytoplasmic vacuolation in the adrenal cortical region in group 4 males were observed. Because of pathological changes in male liver and hematological changes in females, the no-observedadverse-effect level (NOAEL) was concluded to be $0.19 \%$ in the diet $(120 \mathrm{mg} / \mathrm{kg}$ for male rats and $130 \mathrm{mg} / \mathrm{kg}$ body weight/day for female rats) [220]. Since, most of the studies have been in favor of tocotrienols, however, it needs to be replicated in human populations to evaluate the safety and efficacy of tocotrienols as a therapeutic agent or drug.

There are convincing evidence that tocotrienols are detectable at appreciable levels in the plasma after short term and long term supplementations. However, there is insufficient data on the range of plasma concentrations of tocotrienols that are adequate to demonstrate significant physiological effects. Although the pharmacokinetics of tocotrienols are distinctly different from tocopherols which are well studied and remained longer in blood circulation, biodistribution study showed considerable accumulation of tocotrienols in vital organs. In the perspective of therapeutic efficacy, it is evident that the outcome of clinical evaluations is not only affected by the bioavailability of tocotrienols. In view of the limited understanding, more studies on the mechanisms of absorption are essential [221].

In an effort to determine the therapeutic window for tocotrienols, a number of long term clinical studies have been carried out using TRF and tocotrienol derivatives. The majority of these trials were focused on lipid profile as tocotrienols were found to inhibit HMG-CoA reductase [76-78]. However, the optimum dosing regimen to induce therapeutic effects remained unclear.

Although most studies were conducted in rodents and animals, they serve as a basis for clinical evaluations to establish their health benefits in humans. A number of clinical trials were conducted to examine the multifaceted health benefits of tocotrienols in different populations. The bioavailability and efficacy of TRF may vary in different populations. tocotrienols seem to respond differently to a range of age groups but did not show consistent efficacies in the target study populations. Most of the studies conducted in patients with chronic diseases had relatively small sample size. This demonstrates the need to conduct randomized controlled trials in larger population to confidently evaluate the therapeutic potentials of tocotrienols [221].

Patel et al. [190] have determined the concentrations of TE (200 mg mixed TE, b.i.d.) and TCP [200 mg a-TCP, b.i.d.)] in vital tissues and organs of adults receiving oral supplementation. Skin and serum vitamin E concentrations were determined from healthy participants following $12 \mathrm{wk}$ of oral supplementation of TE or TCP. The vitamin $E$ levels in vital organ were determined by HPLC in adipose, brain, cardiac muscle, and liver of surgical patients following oral TE or TCP supplementation (mean duration, $20 \mathrm{wk}$; range, 1-96 wk). Oral supplementation of TE significantly increased the TE tissue concentrations in blood, skin, adipose, brain, cardiac muscle, and liver over time. a-TE was delivered to human brain at a concentration reported to be neuroprotective in experimental models of stroke. The finding of the study is the foundation for Phase II clinical trials testing the efficacy of TE against stroke and end-stage liver disease in humans [190]. Their work provides the first evidence on tissue availability of TE in vital organs of adult humans following oral supplementation to characterize multiple vital organ concentration of TCP in adults. TE was delivered and accumulated in vital human organs supports future studies to identify specific mechanisms of tissue delivery and metabolism. The outcomes of this work provide clear evidence that oral TE supplementation enriches its concentration in whole blood, adipose, skin, brain, cardiac muscle, and liver [190].

\section{Conclusion}

In recent years, the basic research on vitamin $E$ has expanded from primarily focusing on $\alpha \mathrm{T}$ and its antioxidant effects to investigation of different tocopherols and tocotrienols, their metabolism, and their non-antioxidant activities including anti-inflammatory properties. Despite well-documented beneficial effects $[3,220]$, as well as negative association between $\alpha \mathrm{T}$ intake and chronic diseases, supplementation with $\alpha \mathrm{T}$ has failed to offer consistent benefits for the prevention of chronic diseases, including cancer and cardiovascular diseases, in many large clinical intervention studies [4,5,222,223]. $\alpha \mathrm{T}$ may be beneficial to individuals with deficiency of $\alpha \mathrm{T}$ and/ or other micronutrients [220], that can be caused by low dietary intake of this vitamin $\mathrm{E}$ or depletion of $\alpha \mathrm{T}$ due to 
pathological condition or malnutrition associated with smoking, alcoholism, and malabsorption. Under these subclinical conditions, $\alpha \mathrm{T}$ supplementation is likely to be beneficial, as indicated in the Linxian study in a population with deficiencies of micronutrients [224] and the ATBC study including heavy smokers [225]. On the other hand, $\alpha \mathrm{T}$ supplementation did not show beneficial effects in people with adequate nutrient status $[4,5]$.

In contrast to $\alpha \mathrm{T}$, despite no evidence that deficiency of other vitamin $\mathrm{E}$ forms would result in obvious clinical symptoms, accumulating evidence suggests that $\gamma \mathrm{T}, \delta \mathrm{T}$, and tocotrienols seem to have unique properties that are superior to $\alpha \mathrm{T}$ and relevant to prevention and therapy against chronic diseases even under conditions with adequate $\alpha \mathrm{T}$ status. It is noteworthy that these bioactivities of tocopherols and tocotrienols including anti-inflammatory properties have been identified by mechanistic studies and subsequently substantiated in some preclinical models as well as clinical studies [44].

Hence, tocotrienols possess neuroprotective, antioxidant, anti-cancer and cholesterol lowering properties. Tocotrienols are thought to have more potent antioxidant and free radical scavenging properties due to their better distribution in the lipid layers of the cell membrane. In spite of the promising potential, the experimental analysis of tocotrienols accounts for only a small portion of vitamin E research. However, recent studies have enforced a serious reconsideration of this conventional perception and this review article will go a long way in reiterating research pursuit.

\section{Competing interests}

The authors declare that they have no competing interests.

\section{Authors' contributions}

HA drafted the script and collected literature on the subject. AA collected and compiled the relevant information. JI contributed with critical assessment on the subject based on published work in the area. WAS participated in collection of data, manuscript preparation and final drafting. All authors read and approved the final manuscript.

\section{Acknowledgements}

The authors wish to acknowledge the reviewers for their evaluation, comments and suggestions for improving the manuscript

\section{Author details}

${ }^{1}$ Department of Biochemistry, Faculty of Dentistry, Jamia Millia Islamia, New Delhi 110025, India. ${ }^{2}$ Department of Biochemistry, Jamia Hamdard (Hamdard University), New Delhi 110062, India. ${ }^{3}$ Department of Cell Biology and Pediatrics, SUNY Downstate Medical Center, Brooklyn, NY 11203, USA.

Received: 4 June 2014 Accepted: 15 October 2014

Published: 12 November 2014

\section{References}

1. Evans HM, Bishop KS: On the existence of a hitherto unrecognized dietary factor essential for reproduction. Science 1922, 56:650-651.

2. Evans HM, Emerson $\mathrm{OH}$, Emerson GA: The isolation from wheat germ oil of an alcohol, a-tocopherol, having the properties of vitamin E. J Biol Chem 1936, 113(1):319-332.

3. Whittle KJ, Dunphy PJ, Pennock JF: The isolation and properties of delta-tocotrienol from Hevea latex. Biochem J 1966, 100(1):138-145.
4. Qureshi AA, Burger WC, Peterson DM, Elson CE: The structure of an inhibitor of cholesterol biosynthesis isolated from barley. J Biol Chem 1986, 261(23):10544-10550.

5. Guthrie N, Gapor A, Chambers AF, Carroll KK: Inhibition of proliferation of estrogen receptor-negative MDA-MB-435 and -positive MCF-7 human breast cancer cells by palm oil tocotrienols and tamoxifen, alone and in combination. J Nutr 1997, 127(3):544S-548S.

6. Kato A, Gapor A, Tanabe K, Yamaoka M, Mamuro H: Esterified \&alpha-tocopherol and tocotrienols in palm oils. J Jpn Oil Chem Soc 1981, 30(9):590-591.

7. Qureshi AA, Mo H, Packer L, Peterson DM: Isolation and identification of novel tocotrienols from rice bran with hypocholesterolemic, antioxidant, and antitumor properties. J Agric Food Chem 2000, 48(8):3130-3140.

8. Tan B, Brzuskiewicz L: Separation of tocopherol and tocotrienol isomers using normal- and reverse-phase liquid chromatography. Anal Biochem 1989, 180(2):368-373.

9. Aggarwal BB, Sundaram C, Prasad S, Kannappan R: Tocotrienols, the vitamin $E$ of the 21 st century: its potential against cancer and other chronic diseases. Biochem Pharmacol 2010, 80(11):1613-1631.

10. Sen CK, Khanna S, Roy S: Tocotrienols: vitamin E beyond tocopherols. Life Sci 2006, 78(18):2088-2098.

11. Pearce BC, Parker RA, Deason ME, Dischino DD, Gillespie E, Qureshi AA, Volk K, Wright JJ: Inhibitors of cholesterol biosynthesis. 2. Hypocholesterolemic and antioxidant activities of benzopyran and tetrahydronaphthalene analogues of the tocotrienols. J Med Chem 1994, 37(4):526-541.

12. Pearce BC, Parker RA, Deason ME, Qureshi AA, Wright JJ: Hypocholesterolemic activity of synthetic and natural tocotrienols. J Med Chem 1992, 35(20):3595-3606.

13. Serbinova E, Kagan V, Han D, Packer L: Free radical recycling and intramembrane mobility in the antioxidant properties of alphatocopherol and alpha-tocotrienol. Free Radic Biol Med 1991, 10(5):263-275.

14. Serbinova EA, Packer L: Antioxidant properties of alpha-tocopherol and alpha-tocotrienol. Methods Enzymol 1994, 234:354-366.

15. Suzuki YJ, Tsuchiya M, Wassall SR, Choo YM, Govil G, Kagan VE, Packer L: Structural and dynamic membrane properties of alpha-tocopherol and alpha-tocotrienol: implication to the molecular mechanism of their antioxidant potency. Biochemistry 1993, 32(40):10692-10699.

16. Hensley K, Benaksas EJ, Bolli R, Comp P, Grammas P, Hamdheydari L, Mou S, Pye QN, Stoddard MF, Wallis G, Williamson KS, West M, Wechter WJ, Floyd RA: New perspectives on vitamin E: gamma-tocopherol and carboxyelthylhydroxychroman metabolites in biology and medicine. Free Rad Biol Med 2004, 36(1):1-15.

17. Morris VC, Levander OA: Selenium content of foods. J Nutr 1970, 100:1383-1388.

18. Schrauzer GN: Nutritional selenium supplements: product types, quality, and safety. J Am Coll Nutr 2001, 20:1-4.

19. Harris PL, Quaife ML, Swanson WJ: Vitamin E content of foods. J Nutr 1950, 40:367-381.

20. Reagan-Shaw S, Nihal M, Ahsan $H$, Mukhtar $H$, Ahmad N: Combination of vitamin $\mathrm{E}$ and selenium causes an induction of apoptosis of human prostate cancer cells by enhancing Bax/Bcl-2 ratio. Prostate 2008, 68(15):1624-1634.

21. Heinonen OP, Albanes D, Virtamo J, Taylor PR, Huttunen JK, Hartman AM, Haapakoski J, Malila N, Rautalahti M, Ripatti S, Mäenpää H, Teerenhovi L, Koss L, Virolainen M, Edwards BK: Prostate cancer and supplementation with alpha-tocopherol and beta-carotene: incidence and mortality in a controlled trial. J Natl Cancer Inst 1998, 90:440-446.

22. Meyer F, Galan P, Douville P, Bairati I, Kegle P, Bertrais S, Estaquio C, Hercberg S: Antioxidant vitamin and mineral supplementation and prostate cancer prevention in the SU.VI.-MAX trial. Int J Cancer 2005, 116:182-186.

23. Heart Protection Study Collaborative Group: MRC/BHF Heart Protection Study of antioxidant vitamin supplementation in 20,536 high-risk individuals: a randomised placebo-controlled trial. Lancet 2002, 360:23-33.

24. Rodriguez C, Jacobs EJ, Mondul AM, Calle EE, McCullough ML, Thun MJ: Vitamin E supplements and risk of prostate cancer in U.S. men. Cancer Epidemiol Biomarker Prev 2004, 13:378-382.

25. The HOPE and HOPE-TOO Trial Investigators: Effects of long term vitamin E supplementation on cardiovascular events and cancer: a randomized controlled trial. JAMA 2005, 293:1338-1347. 
26. Wright ME, Weinstein SJ, Lawson KA, Albanes D, Subar AF, Dixon LB, Mouw T, Schatzkin A, Leitzmann MF: Supplemental and dietary vitamin e intakes and risk of prostate cancer in a large prospective study. Cancer Epidemiol Biomarkers Prev 2007, 16:1128-1135.

27. Lippman SM, Klein EA, Goodman PJ, Lucia MS, Thompson IM, Ford LG, Parnes HL, Minasian LM, Gaziano JM, Hartline JA, Parsons JK, Bearden JD III, Crawford ED, Goodman GE, Claudio J, Winquist E, Cook ED, Karp DD, Walther P, Lieber MM, Kristal AR, Darke AK, Arnold KB, Ganz PA, Santella RM, Albanes D, Taylor PR, Probstfield JL, Jagpal TJ, Crowley JJ, et al: Effect of selenium and vitamin E on risk of prostate cancer and other cancers: the Selenium and Vitamin E Cancer Prevention Trial (SELECT). JAMA 2009, 301:39-51.

28. Ledesma MC, Jung-Hynes B, Schmit TL, Kumar R, Mukhtar H, Ahmad N: Selenium and vitamin E for prostate cancer: post-SELECT (Selenium and Vitamin E Cancer Prevention Trial) status. Mol Med 2011, 17(1-2):134-143.

29. Theriault A, Chao JT, Wang Q, Gapor A, Adeli K: Tocotrienol: a review of its therapeutic potential. Clin Biochem 1999, 32(5):309-319.

30. Jensen SK, Lauridsen C: Alpha-tocopherol stereoisomers. Vitam Horm 2007, 76:281-308

31. Joffe $M$, Harris P: The biological potency of the natural tocopherols and certain derivatives. J Am Chem Soc 1943, 65:925-927.

32. Burton $G$, Ingold $K$ : The antioxidant activity of vitamin $E$ and relative chain-breaking phenolic antioxidants in vitro. J Am Chem Soc 1981, 103:6472-6477.

33. Hosomi A, Arita M, Sato Y, Kiyose C, Ueda T, Igarashi O, Arai H, Inoue K: Affinity for alpha-tocopherol transfer protein as a determinant of the biological activities of vitamin E analogs. FEBS Lett 1997, 409:105-108.

34. Lee E, Choi MK, Lee YJ, Ku JL, Kim KH, Choi JS, Lim SJ: Alpha-tocopheryl succinate, in contrast to alpha-tocopherol and alphatocopheryl acetate, inhibits prostaglandin E2 production in human lung epithelial cells. Carcinogenesis 2006, 27:2308-2315.

35. Bendich A, Machlin L: Safety of oral intake of vitamin E. Am J Clin Nutr $1988,48: 612-619$

36. Wechter WJ, Kantoci D, Murray ED Jr, D'Amico DC, Jung ME, Wang WH: A new endogenous natriuretic factor: LLU-a. Proc Natl Acad Sci U S A 1996, 93:6002-6007.

37. Freiser $\mathrm{H}$, Jiang $\mathrm{Q}$ : Gamma-tocotrienol and gamma-tocopherol are primarily metabolized to conjugated 2-(beta-carboxyethyl)-6-hydroxy-2,7,8tri methyl chroman and sulfated long-chain carboxy chromanols in rats. J Nutr 2009, 139:884-889.

38. Bardowell SA, Ding X, Parker RS: Disruption of P450-mediated vitamin E hydroxylase activities alters vitaminE status in tocopherol supplemented mice and reveals extra-hepatic vitamin E metabolism. J Lipid Res 2012, 53:2667-2676.

39. Bardowell SA, Duan F, Manor D: Disruption of mouse cytochrome p4504f14(Cyp4f14gene) causes severe perturbations in vitamin $E$ metabolism. J Biol Chem 2012, 287:26077-26086.

40. Jiang Q, Jiang Z, Hall YJ, Jang Y, Snyder PW, Bain C, Huang J, Jannasch A, Cooper B, Wang Y, Ten Moreland MS, Ames BN: $\gamma$-Tocopherol attenuates moderate but not severe colitis and suppresses moderate colitis-promoted colon tumorigenesis in mice. Free Radic Biol Med 2013, 65:1069-1077.

41. Jiang Q, Yin X, Lill MA, Danielson ML, Freiser H, Huang J: Long-chain carboxychromanols, metabolites of vitamin $\mathrm{E}$, are potent inhibitors of cyclooxygenases. Proc Natl Acad Sci U S A 2008, 105:20464-20469.

42. Jiang $Z$, Yin $X$, Jiang Q: Natural forms of vitamin $E$ and 130-carboxychro manol, a long-chain vitamin $E$ metabolite, inhibit leukotriene generation from stimulated neutrophils by blocking calcium in flux and suppressing 5- lipoxygenase activity, respectively. J Immunol 2011, 186:1173-1179.

43. Birringer $M$, Lington $D$, Vertuani $S$, Manfredini S, Scharlau D, Glei M, Ristow M: Proapoptotic effects of long-chain vitamin E metabolites in HepG2 cells are mediated by oxidative stress. Free Radic Biol Med 2010 49:1315-1322

44. Jiang Q: Natural forms of vitamin E: metabolism, antioxidant, and anti-inflammatory activities and their role in disease prevention and therapy. Free Radic Biol Med 2014, 72C:76-90.

45. Galli F, Azzi A: Present trends in vitamin E research. Biofactors 2010, 36:33-42.

46. Ju J, Picinich SC, Yang Z, Zhao Y, Suh N, Kong AN, Yang CS: Cancerpreventive activities of tocopherols and tocotrienols. Carcinogenesis 2010, 31:533-542

47. Constantinou C, Papas A, Constantinou Al: Vitamin E and cancer: an insight into the anticancer activities of vitamin $E$ isomers and analogs. Int J Cancer 2008, 123:739-752.
48. Barve A, Khor TO, Nair S, Reuhl K, Suh N, Reddy B, Newmark H, Kong AN: Gamma-tocopherol-enriched mixed tocopherol diet inhibits prostate carcinogenesis in TRAMP mice. Int J Cancer 2009, 124:1693-1699.

49. Lu G, Xiao H, Li GX, Picinich SC, Chen YK, Liu A, Lee MJ, Loy S, Yang CS: A gamma-tocopherol-rich mixture of tocopherols inhibits chemically induced lung tumorigenesis in $\mathrm{A} / \mathrm{J}$ mice and xenograft tumor growth. Carcinogenesis 2010, 31:687-694.

50. Yu W, Jia L, Park SK, Li J, Gopalan A, Simmons-Menchaca M, Sanders BG Kline K: Anticancer actions of natural and synthetic vitamin $E$ forms: RRR-alpha- tocopherol blocks the anticancer actions of gamma-tocopherol. Mol Nutr Food Res 2009, 53:1573-1581.

51. Jiang $Q$, Moreland $M, A$ mes $B N$, Yin $X$ : A combination of aspirin and gamma-tocopherol is superior to that of aspirin and alpha-tocopherol in anti-inflammatory action and attenuation of aspirin-induced adverse effects. J Nutr Biochem 2009, 20:894-900.

52. Cooney RV, Franke AA, Harwood PJ, Hatch-Pigott V, Custer LJ, Mordan LJ: Gamma-tocopherol detoxification of nitrogen dioxide: superiority to alpha-tocopherol. Proc Natl Acad Sci U S A 1993, 90:1771-1775.

53. Christen S, Woodall AA, Shigenaga MK, Southwell-Keely PT, Duncan MW, Ames BN: Gamma-tocopherol traps mutagenic electrophiles such as NO (X) and complements alpha-tocopherol: physiological implications. Proc Natl Acad Sci U S A 1997, 94:3217-3222.

54. Jiang Q, Christen S, Shigenaga MK, Ames BN: Gamma-Tocopherol, the major form of vitamin $\mathrm{E}$ in the US diet, deserves more attention. Am J Clin Nutr 2001, 74:714-722.

55. Brigelius-Flohe R, Traber MG: Vitamin E: function and metabolism. FASEB J 1999, 13:1145-1155.

56. Moya-Camarena SY, Jiang Q: The role of vitamin E forms in cancer prevention and therapy-studies in human intervention trials and animal models. In Nutraceuticals and Cancer. Edited by Sarkar FH. New York: Springer; 2012:323-354

57. Myung SK, Ju W, Cho B, Oh SW, Park SM, Koo BK, Park BJ, Korean Meta-Analysis Study Group: Efficacy of vitamin and antioxidant supplements in prevention of cardiovascular disease: systematic review and meta-analysis of randomised controlled trials. BMJ 2013, 346:f10

58. Atkinson J, Epand RF, Epand RM: Tocopherols and tocotrienols in membranes: a critical review. Free Radic Biol Med 2008, 44(5):739-764.

59. Qureshi AA, Bradlow BA, Brace L, Manganello J, Peterson DM, Pearce BC, Wright JJ, Gapor A, Elson CE: Response of hypercholesterolemic subjects to administration of tocotrienols. Lipids 1995, 30(12):1171-1177.

60. Agarwal MK, Agarwal ML, Athar M, Gupta S: Tocotrienol-rich fraction of palm oil activates $\mathrm{p} 53$, modulates $\mathrm{Bax} / \mathrm{Bcl} 2$ ratio and induces apoptosis independent of cell cycle association. Cell Cycle 2004, 3(2):205-211.

61. Comitato R, Leoni G, Canali R, Ambra R, Nesaretnam K, Virgili F: Tocotrienols activity in MCF-7 breast cancer cells: involvement of ERbeta signal transduction. Mol Nutr Food Res 2010, 54(5):669-678.

62. Shun MC, Yu W, Gapor A, Parsons R, Atkinson J, Sanders BG, Kline K Pro-apoptotic mechanisms of action of a novel vitamin $E$ analog (alpha-TEA) and a naturally occurring form of vitamin E (delta-tocotrienol) in MDA-MB-435 human breast cancer cells. Nutr Cancer 2004, 48(1):95-105.

63. Pierpaoli E, Viola V, Barucca A, Orlando F, Galli F, Provinciali M: Effect of annatto-tocotrienols supplementation on the development of mammary tumors in HER-2/neu transgenic mice. Carcinogenesis 2013, 34(6):1352-1360.

64. Samant GV, Wali VB, Sylvester PW: Anti-proliferative effects of gamma-tocotrienol on mammary tumour cells are associated with suppression of cell cycle progression. Cell Prolif 2010, 43(1):77-83.

65. Elangovan S, Hsieh TC, Wu JM: Growth inhibition of human MDA-mB-231 breast cancer cells by delta-tocotrienol is associated with loss of cyclin D1/CDK4 expression and accompanying changes in the state of phosphorylation of the retinoblastoma tumor suppressor gene product. Anticancer Res 2008, 28(5A):2641-2647.

66. Wali VB, Bachawal SV, Sylvester PW: Combined treatment of gamma-tocotrienol with statins induce mammary tumor cell cycle arrest in G1. Exp Biol Med (Maywood) 2009, 234(6):639-650.

67. Xu WL, Liu JR, Liu HK, Qi GY, Sun XR, Sun WG, Chen BQ: Inhibition of proliferation and induction of apoptosis by gamma-tocotrienol in human colon carcinoma HT-29 cells. Nutrition 2009, 25(5):555-566.

68. Sakai M, Okabe M, Tachibana H, Yamada K: Apoptosis induction by gamma-tocotrienol in human hepatoma Hep3B cells. J Nutr Biochem 2006, 17(10):672-676. 
69. Sun W, Wang Q, Chen B, Liu J, Liu H, Xu W: Gamma-tocotrienol-induced apoptosis in human gastric cancer SGC-7901 cells is associated with a suppression in mitogen-activated protein kinase signalling. $\mathrm{Br}$ J Nutr 2008, 99(6):1247-1254.

70. Wada S, Satomi Y, Murakoshi M, Noguchi N, Yoshikawa T, Nishino H: Tumor suppressive effects of tocotrienol in vivo and in vitro. Cancer Lett 2005, 229(2):181-191.

71. Kashiwagi K, Harada K, Yano Y, Kumadaki I, Hagiwara K, Takebayashi J, Kido W, Virgona N, Yano T: A redox-silent analogue of tocotrienol inhibits hypoxic adaptation of lung cancer cells. Biochem Biophys Res Commun 2008, 365(4):875-881.

72. Nakashima K, Virgona N, Miyazawa M, Watanabe T, Yano T: The tocotrienolrich fraction from rice bran enhances cisplatin-induced cytotoxicity in human mesothelioma H28 cells. Phytother Res 2010, 24(9):1317-1321.

73. Chang PN, Yap WN, Lee DT, Ling MT, Wong YC, Yap YL: Evidence of gamma-tocotrienol as an apoptosis-inducing, invasion-suppressing, and chemotherapy drug-sensitizing agent in human melanoma cells. Nutr Cancer 2009, 61(3):357-366.

74. McAnally JA, Gupta J, Sodhani S, Bravo L, Mo H: Tocotrienols potentiate lovastatin-mediated growth suppression in vitro and in vivo. Exp Biol Med (Maywood) 2007, 232(4):523-531.

75. Hussein D, Mo H: d-delta-Tocotrienol-mediated suppression of the proliferation of human PANC-1, MIA PaCa-2, and BxPC-3 pancreatic carcinoma cells. Pancreas 2009, 38(4):e124-e136.

76. Constantinou C, Hyatt JA, Vraka PS, Papas A, Papas KA, Neophytou C, Hadjivassiliou V, Constantinou Al: Induction of caspase-independent programmed cell death by vitamin E natural homologs and synthetic derivatives. Nutr Cancer 2009, 61(6):864-874.

77. Nesaretnam K, Stephen R, Dils R, Darbre P: Tocotrienols inhibit the growth of human breast cancer cells irrespective of estrogen receptor status. Lipids 1998, 33(5):461-469.

78. Wada S: Chemoprevention of tocotrienols: the mechanism of antiproliferative effects. Forum Nutr 2009, 61:204-216.

79. Wali VB, Bachawal SV, Sylvester PW: Endoplasmic reticulum stress mediates gamma-tocotrienol-induced apoptosis in mammary tumor cells. Apoptosis 2009, 14(11):1366-1377.

80. Comitato R, Nesaretnam K, Leoni G, Ambra R, Canali R, Bolli A, Marino M, Virgili F: A novel mechanism of natural vitamin $E$ tocotrienol activity: involvement of ERbeta signal transduction. Am J Physiol Endocrinol Metab 2009, 297(2):E427-E437.

81. Nakagawa K, Shibata A, Yamashita S, Tsuzuki T, Kariya J, Oikawa S, Miyazawa T: In vivo angiogenesis is suppressed by unsaturated vitamin $\mathrm{E}_{\text {, }}$ tocotrienol. J Nutr 2007, 137(8):1938-1943.

82. Weng-Yew W, Selvaduray KR, Ming CH, Nesaretnam K: Suppression of tumor growth by palm tocotrienols via the attenuation of angiogenesis. Nutr Cancer 2009, 61(3):367-373.

83. Har CH, Keong CK: Effects of tocotrienols on cell viability and apoptosis in normal murine liver cells (BNL CL.2) and liver cancer cells (BNL 1ME A.7R.1), in vitro. Asia Pac J Clin Nutr 2005, 14(4):374-380

84. Wali VB, Bachawal SV, Sylvester PW: Suppression in mevalonate synthesis mediates antitumor effects of combined statin and gamma-tocotrienol treatment. Lipids 2009, 44(10):925-934.

85. Bachawal SV, Wali VB, Sylvester PW: Combined gamma-tocotrienol and erlotinib/gefitinib treatment suppresses Stat and Akt signaling in murine mammary tumor cells. Anticancer Res 2010, 30(2):429-437.

86. Rashid SA, Halim AS, Muhammad NA, Suppl A: The effect of vitamin E on basic fibroblast growth factor level in human fibroblast cell culture. Med J Malaysia 2008, 63:69-70

87. Pierpaoli E, Viola V, Pilolli F, Piroddi M, Galli F, Provinciali M: Gamma- and delta-tocotrienols exert a more potent anticancer effect than alphatocopheryl succinate on breast cancer cell lines irrespective of HER-2/neu expression. Life Sci 2010, 86(17-18):668-675.

88. Wu SJ, Ng LT: Tocotrienols inhibited growth and induced apoptosis in human HeLa cells through the cell cycle signaling pathway. Integr Cancer Ther 2010, 9(1):66-72.

89. Eitsuka T, Nakagawa K, Miyazawa T: Down-regulation of telomerase activity in DLD-1 human colorectal adenocarcinoma cells by tocotrienol. Biochem Biophys Res Commun 2006, 348(1):170-175.

90. Stolzenberg-Solomon RZ, Sheffler-Collins S, Weinstein S, Garabrant DH, Mannisto S, Taylor P, Virtamo J, Albanes D: Vitamin E intake, alpha- tocopherol status, and pancreatic cancer in a cohort of male smokers. Am J Clin Nutr 2009, 89(2):584-591.

91. Kunnumakkara AB, Guha S, Krishnan S, Diagaradjane P, Gelovani J, Aggarwal BB: Curcumin potentiates antitumor activity of gemcitabine in an orthotopic model of pancreatic cancer through suppression of proliferation, angiogenesis, and inhibition of nuclear factor-kappaBregulated gene products. Cancer Res 2007, 67:3853-3861.

92. Mahon PC, Baril P, Bhakta V, Chelala C, Caulee K, Harada T, Lemoine NR: S100A4 contributes to the suppression of BNIP3 expression, chemoresistance, and inhibition of apoptosis in pancreatic cancer. Cancer Res 2007, 67:6786-6795.

93. Kürbitz C, Heise D, Redmer T, Goumas F, Arlt A, Lemke J, Rimbach G Kalthoff $\mathrm{H}$, Trauzold A: Epicatechin gallate and catechin gallate are superior to epigallocatechin gallate in growth suppression and anti-inflammatory activities in pancreatic tumor cells. Cancer Sci 2011, 102:728-734.

94. Murtaza I, Adhami VM, Hafeez BB, Saleem M, Mukhtar H: Fisetin, a natural flavonoid, targets chemoresistant human pancreatic cancer AsPC-1 cells through DR3-mediated inhibition of NF-kappaB. Int J Cancer 2009 125:2465-2473.

95. Miyazawa T, Shibata A, Sookwong P, Kawakami Y, Eitsuka T, Asai A, Oikawa S, Nakagawa K: Antiangiogenic and anticancer potential of unsaturated vitamin E (tocotrienol). J Nutr Biochem 2009, 20:79-86.

96. Ling MT, Luk SU, Al-Ejeh F, Khanna KK: Tocotrienol as a potential anticancer agent. Carcinogenesis 2012, 33(2):233-239.

97. Husain K, Francois RA, Hutchinson SZ, Neuger AM, Lush R, Coppola D, Sebti S, Malafa MP: Vitamin E delta-tocotrienol levels in tumor and pancreatic tissue of mice after oral administration. Pharmacology 2009, 83:157-163.

98. Husain K, Francois RA, Yamauchi T, Perez M, Sebti SM, Malafa MP: Vitamin E $\delta$-tocotrienol augments the antitumor activity of gemcitabine and suppresses constitutive NF-KB activation in pancreatic cancer. Mol Cancer Ther 2011, 10(12):2363-2372.

99. Nesaretnam K, Meganathan P, Veerasenan SD, Selvaduray KR: Tocotrienols and breast cancer: the evidence to date. Genes Nutr 2012, 7(1):3-9.

100. Nesaretnam K, Selvaduray KR, Abdul Razak G, Veerasenan SD, Gomez PA Effectiveness of tocotrienol-rich fraction combined with tamoxifen in the management of women with early breast cancer: a pilot clinical trial. Breast Cancer Res 2010, 12(5):R81.

101. Ahn KS, Sethi G, Krishnan K, Aggarwal BB: Gamma-tocotrienol inhibits nuclear factor-kappaB signaling pathway through inhibition of receptor-interacting protein and TAK1 leading to suppression of antiapoptotic gene products and potentiation of apoptosis. $J$ Biol Chem 2007, 282(1):809-820.

102. Shirode AB, Sylvester PW: Synergistic anticancer effects of combined $\gamma$-tocotrienol and celecoxib treatment are associated with suppression in Akt and NFkB signaling. Biomed Pharmacother 2010, 64(5):327-332.

103. Kuhad A, Chopra K: Attenuation of diabetic nephropathy by tocotrienol: involvement of NFkB signaling pathway. Life Sci 2009, 84(9-10):296-301.

104. Norazlina M, Lee PL, Lukman HI, Nazrun AS, Ima-Nirwana S: Effects of vitamin $E$ supplementation on bone metabolism in nicotine-treated rats. Singapore Med J 2007, 48(3):195-199.

105. Ahmad NS, Khalid BA, Luke DA, Ima Nirwana S: Tocotrienol offers better protection than tocopherol from free radical-induced damage of rat bone. Clin Exp Pharmacol Physiol 2005, 32(9):761-770.

106. Shibata A, Nakagawa K, Sookwong P, Tsuduki T, Tomita S, Shirakawa H, Komai M, Miyazawa T: Tocotrienol inhibits secretion of angiogenic factors from human colorectal adenocarcinoma cells by suppressing hypoxia-inducible factor-1alpha. J Nutr 2008, 138(11):2136-2142.

107. Wu SJ, Liu PL, Ng LT: Tocotrienol-rich fraction of palm oil exhibits anti-inflammatory property by suppressing the expression of inflammatory mediators in human monocytic cells. Mol Nutr Food Res 2008, 52(8):921-929.

108. Lee SP, Mar GY, Ng LT: Effects of tocotrienol-rich fraction on exercise endurance capacity and oxidative stress in forced swimming rats. Eur J Appl Physiol 2009, 107(5):587-595.

109. Newaz MA, Nawal NN: Effect of gamma-tocotrienol on blood pressure, lipid peroxidation and total antioxidant status in spontaneously hypertensive rats (SHR). Clin Exp Hypertens 1999, 21(8):1297-1313.

110. Hsieh TC, Wu JM: Suppression of cell proliferation and gene expression by combinatorial synergy of EGCG, resveratrol and gamma-tocotrienol in 
estrogen receptor-positive MCF-7 breast cancer cells. Int J Oncol 2008, 33(4):851-859.

111. Adam A, Marzuki A, Ngah WZ, Top GM: Nitrofurantoin-induced hepatic and pulmonary biochemical changes in mice fed different vitamin $\mathrm{E}$ doses. Pharmacol Toxicol 1996, 79(6):334-339.

112. Renuka Devi R, Arumughan C: Antiradical efficacy of phytochemical extracts from defatted rice bran. Food Chem Toxicol 2007, 45(10):2014-2021.

113. Ngah WZ, Jarien Z, San MM, Marzuki A, Top GM, Shamaan NA, Kadir KA: Effect of tocotrienols on hepatocarcinogenesis induced by 2-acetylaminofluorene in rats. Am J Clin Nutr 1991 53(4 Suppl):1076S-1081S.

114. Shamaan NA, Wan Ngah WZ, Ibrahim R, Jarien Z, Top AG, Abdul Kadir K: Effect of tocotrienol on the activities of cytosolic glutathione-dependent enzymes in rats treated with 2-acetylaminofluorene. Biochem Pharmacol 1993, 45(7):1517-1519.

115. Makpol S, Shamaan NA, Jarien Z, Top AG, Khalid BA, Wan Ngah WZ: Different starting times of alpha-tocopherol and gamma-tocotrienol supplementation and tumor marker enzyme activities in the rat chemically induced with cancer. Gen Pharmacol 1997, 28(4):589-592.

116. Ong FB, Wan Ngah WZ, Shamaan NA, Md Top AG, Marzuki A, Khalid AK: Glutathione S-transferase and gamma-glutamyl transpeptidase activities in cultured rat hepatocytes treated with tocotrienol and tocopherol. Comp Biochem Physiol Part C Pharmacol Toxicol Endocrinol 1993, 106(1):237-240.

117. Palozza P, Verdecchia S, Avanzi L, Vertuani S, Serini S, lannone A, Manfredini S: Comparative antioxidant activity of tocotrienols and the novel chromanyl-polyisoprenyl molecule FeAox-6 in isolated membranes and intact cells. Mol Cell Biochem 2006, 287(1-2):21-32.

118. Osakada F, Hashino A, Kume T, Katsuki H, Kaneko S, Akaike A: Alpha-tocotrienol provides the most potent neuroprotection among vitamin E analogs on cultured striatal neurons. Neuropharmacology 2004, 47(6):904-915

119. Nakano M, Onodera A, Saito E, Tanabe M, Yajima K, Takahashi J, Nguyen VC: Effect of astaxanthin in combination with alpha-tocopherol or ascorbic acid against oxidative damage in diabetic ODS rats. J Nutr Sci Vitaminol (Tokyo) 2008, 54(4):329-334.

120. Wan Nazaimoon WM, Khalid BA: Tocotrienols-rich diet decreases advanced glycosylation end-products in non-diabetic rats and improves glycemic control in streptozotocin-induced diabetic rats. Malays J Pathol 2002, 24(2):77-82.

121. Budin SB, Othman F, Louis SR, Bakar MA, Das S, Mohamed J: The effects of palm oil tocotrienol-rich fraction supplementation on biochemical parameters, oxidative stress and the vascular wall of streptozotocin-induced diabetic rats. Clinics (Sao Paulo) 2009, 64(3):235-244.

122. Kuhad A, Bishnoi M, Tiwari V, Chopra K: Suppression of NF-kappabeta signaling pathway by tocotrienol can prevent diabetes associated cognitive deficits. Pharmacol Biochem Behav 2009, 92(2):251-259.

123. Kuhad A, Chopra K: Tocotrienol attenuates oxidative-nitrosative stress and inflammatory cascade in experimental model of diabetic neuropathy. Neuropharmacology 2009, 57(4):456-462.

124. Tiwari V, Kuhad A, Bishnoi M, Chopra K: Chronic treatment with tocotrienol, an isoform of vitamin $\mathrm{E}$, prevents intracerebroventricular streptozotocin-induced cognitive impairment and oxidative-nitrosative stress in rats. Pharmacol Biochem Behav 2009, 93(2):183-189.

125. Tiwari V, Kuhad A, Chopra K: Neuroprotective effect of vitamin E isoforms against chronic alcohol-induced peripheral neurotoxicity: possible involvement of oxidative-nitrodative stress. Phytother Res 2012, 26(11):1738-1745.

126. Siddiqui S, Rashid Khan M, Siddiqui WA: Comparative hypoglycemic and nephroprotective effects of tocotrienol rich fraction (TRF) from palm oil and rice bran oil against hyperglycemia induced nephropathy in type 1 diabetic rats. Chem Biol Interact 2010, 188(3):651-658.

127. Siddiqui $\mathrm{S}$, Ahsan $\mathrm{H}$, Khan MR, Siddiqui WA: Protective effects of tocotrienols against lipid-induced nephropathy in experimental type-2 diabetic rats by modulation in TGF-beta expression. Toxicol Appl Pharmacol 2013, 273(2):314-324.

128. Kanaya $Y$, Doi T, Sasaki H, Fujita A, Matsuno S, Okamoto K, Nakano $Y$, Tsujiwaki S, Furuta H, Nishi M, Tsuno T, Taniguchi H, Nanjo K: Rice bran extract prevents the elevation of plasma peroxylipid in KKAy diabetic mice. Diabetes Res Clin Pract 2004, 66(Suppl 1):S157-S160.
129. Yoshida Y, Hayakawa M, Habuchi Y, Itoh N, Niki E: Evaluation of lipophilic antioxidant efficacy in vivo by the biomarkers hydroxyoctadecadienoic acid and isoprostane. Lipids 2007, 42(5):463-472.

130. Fang F, Kang Z, Wong C: Vitamin E tocotrienols improve insulin sensitivity through activating peroxisome proliferator-activated receptors. Mol Nutr Food Res 2010, 54(3):345-352.

131. Qureshi AA, Qureshi N, Hasler-Rapacz JO, Weber FE, Chaudhary V, Crenshaw TD, Gapor A, Ong AS, Chong YH, Peterson D: Dietary tocotrienols reduce concentrations of plasma cholesterol, apolipoprotein B, thromboxane B2, and platelet factor 4 in pigs with inherited hyperlipidemias. Am J Clin Nutr 1991, 53(4 Suppl):1042S-1046S.

132. Qureshi AA, Qureshi N, Wright JJ, Shen Z, Kramer G, Gapor A, Chong YH, DeWitt G, Ong A, Peterson DM: Lowering of serum cholesterol in hypercholesterolemic humans by tocotrienols (palmvitee). Am J Clin Nutr 1991, 53(4 Suppl):1021S-1026S.

133. Hood RL, Sidhu GS: Effects of guar gum and tocotrienols on cholesterol metabolism on the Japanese quail. Nutr Res 1992, 12:117S-127S.

134. Parker RA, Pearce BC, Clark RW, Gordon DA, Wright JJ: Tocotrienols regulate cholesterol production in mammalian cells by posttranscriptional suppression of 3-hydroxy-3-methylglutaryl-coenzyme A reductase. J Biol Chem 1993, 268(15):11230-11238.

135. Qureshi N, Qureshi AA: Novel hypercholesterolemic agents with antioxidant properties. In Vitamin E in Health and Disease. Edited by Packer L, Fuchs J. New York: Marcel Dekker; 1993:247-267.

136. Minhajuddin M, Beg ZH, lqbal J: Hypolipidemic and antioxidant properties of tocotrienol rich fraction isolated from rice bran oil in experimentally induced hyperlipidemic rats. Food Chem Toxicol 2005, 43(5):747-753.

137. Watkins T, Lenz P, Gapor A, Struck M, Tomeo A, Bierenbaum M: Gamma-Tocotrienol as a hypocholesterolemic and antioxidant agent in rats fed atherogenic diets. Lipids 1993, 28(12):1113-1118.

138. Khor HT, Chieng DY, Ong KK: Tocotrienols inhibit HMG-CoA reductase activity in the guinea pig. Nutr Res 1995, 15:537-544.

139. Iqbal J, Minhajuddin M, Beg ZH: Suppression of 7,12-dimethylbenz[alpha] anthracene-induced carcinogenesis and hypercholesterolaemia in rats by tocotrienol-rich fraction isolated from rice bran oil. Eur J Cancer Prev 2003, 12(6):447-453.

140. Magosso E, Ansari MA, Gopalan Y, Shuaib IL, Wong JW, Khan NA, Abu Bakar $\mathrm{MR}, \mathrm{Ng} \mathrm{BH}$, Yuen KH: Tocotrienols for normalisation of hepatic echogenic response in nonalcoholic fatty liver: a randomised placebo-controlled clinical trial. Nutr J 2013, 12(1):166.

141. Burdeos GC, Nakagawa K, Watanabe A, Kimura F, Miyazawa T: Gamma-tocotrienol attenuates triglyceride through effect on lipogenic gene expression in mouse hepatocellular carcinoma Hepa 1-6. J Nutr Sci Vitaminol 2013, 59:148-151.

142. Muto C, Yachi R, Aoki Y, Koike T, Igarashi O, Kiyose C: Gamma-tocotrienol reduces the triacylglycerol level in rat primary hepatocytes through regulation of fatty acid metabolism. J Clin Biochem Nutr 2013, 52(1):32-37.

143. Kooyenga DK, Geller M, Watkins TR, Gapor A, Diakoumakis E, Bierenbaum ML: Palm oil antioxidant effects in patients with hyperlipidaemia and carotid stenosis-2 year experience. Asia Pac J Clin Nutr 1997, 6(1):72-75

144. Tan B, Mueller AM: Tocotrienols in cardiometabolic diseases. In Tocotrienols: Vitamin E beyond Tocopherol. Edited by Watson RR, Preedy VR. AOCS/CRC Press, Taylor and Francis Group; 2008:257-273.

145. Mahalingam D, Radhakrishnan AK, Amom Z, Ibrahim N, Nesaretnam K: Effects of supplementation with tocotrienol-rich fraction on immune response to tetanus toxoid immunization in normal healthy volunteers. Eur J Clin Nutr 2011, 65(1):63-69.

146. Ren Z, Pae M, Dao MC, Smith D, Meydani SN, Wu D: Dietary supplementation with tocotrienols enhances immune function in C57BL/ 6 mice. J Nutr 2010, 140(7):1335-1341.

147. Gu JY, Wakizono Y, Sunada Y, Hung P, Nonaka M, Sugano M, Yamada K: Dietary effect of tocopherols and tocotrienols on the immune function of spleen and mesenteric lymph node lymphocytes in brown Norway rats. Biosci Biotechnol Biochem 1999, 63(10):1697-1702.

148. Radhakrishnan AK, Mahalingam D, Selvaduray KR, Nesaretnam K: Supplementation with natural forms of vitamin e augments antigen-specific Th1-type immune response to tetanus toxoid. Biomed Res Int 2013, 2013:782067. 
149. Vasanthi HR, Parameswari RP, Das DK: Multifaceted role of tocotrienols in cardioprotection supports their structure: function relation. Genes Nutr 2012, 7(1):19-28.

150. Chao JT, Gapor A, Theriault A: Inhibitory effect of delta-tocotrienol, a HMG CoA reductase inhibitor, on monocyte-endothelial cell adhesion. J Nutr Sci Vitaminol (Tokyo) 2002, 48(5):332-337.

151. Theriault A, Chao JT, Gapor A: Tocotrienol is the most effective vitamin $E$ for reducing endothelial expression of adhesion molecules and adhesion to monocytes. Atherosclerosis 2002, 160(1):21-30.

152. Koba K, Abe K, Ikeda I, Sugano M: Effects of alpha-tocopherol and tocotrienols on blood pressure and linoleic acid metabolism in the spontaneously hypertensive rat (SHR). Biosci Biotechnol Biochem 1992, 56(9):1420-1423.

153. Chou TW, Ma CY, Cheng HH, Chen YY, Lai MH: A rice bran oil diet improves lipid abnormalities and suppress hyperinsulinemic responses in rats with streptozotocin/nicotinamide-induced type 2 diabetes. $J$ Clin Biochem Nutr 2009, 45(1):29-36.

154. Nafeeza MI, Norzana AG, Jalaluddin HL, Gapor MT: The effects of a tocotrienol-rich fraction on experimentally induced atherosclerosis in the aorta of rabbits. Malays J Pathol 2001, 23(1):17-25.

155. Das S, Powell SR, Wang P, Divald A, Nesaretnam K, Tosaki A, Cordis GA, Maulik N, Das DK: Cardioprotection with palm tocotrienol: antioxidant activity of tocotrienol is linked with its ability to stabilize proteasomes. Am J Physiol Heart Circ Physiol 2005, 289(1):H361-H367. Retraction in: Am J Physiol Heart Circ Physiol 2012, 302(11):H2447.

156. Qureshi AA, Peterson DM, Hasler-Rapacz JO, Rapacz J: Novel tocotrienols of rice bran suppress cholesterogenesis in hereditary hypercholesterolemic swine. J Nutr 2001, 131(2):223-230.

157. Esterhuyse AJ, du Toit EF, Benadè AJ, Van Rooyen J: Dietary red palm oil improves reperfusion cardiac function in the isolated perfused rat heart of animals fed a high cholesterol diet. Prostaglandins Leukot Essent Fatty Acids 2005, 72(3):153-161.

158. Das M, Das S, Wang P, Powell SR, Das DK: Caveolin and proteasome in tocotrienol mediated myocardial protection. Cell Physiol Biochem 2008, 22(1-4):287-294.

159. Sen CK, Khanna S, Roy S, Packer L: Molecular basis of vitamin E action: tocotrienol potently inhibits glutamate-induced pp 60(c-Src) kinase activation and death of HT4 neuronal cells. J Biol Chem 2000, 275(17):13049-13055.

160. Sen CK, Khanna S, Roy S: Tocotrienol: the natural vitamin E to defend the nervous system? Ann N Y Acad Sci 2004, 1031:127-142.

161. Khanna S, Roy S, Slivka A, Craft TK, Chaki S, Rink C, Notestine MA, DeVries $A C$, Parinandi NL, Sen CK: Neuroprotective properties of the natural vitamin E alpha-tocotrienol. Stroke 2005, 36(10):2258-2264.

162. Khanna S, Roy S, Parinandi NL, Maurer M, Sen CK: Characterization of the potent neuroprotective properties of the natural vitamin $E$ alpha-tocotrienol. J Neurochem 2006, 98(5):1474-1486.

163. Khanna S, Parinandi NL, Kotha SR, Roy S, Rink C, Bibus D, Sen CK: Nanomolar vitamin E alpha-tocotrienol inhibits glutamate-induced activation of phospholipase A2 and causes neuroprotection. J Neurochem 2010, 112(5):1249-1260.

164. Khanna S, Roy S, Park HA, Sen CK: Regulation of c-Src activity in glutamate-induced neurodegeneration. J Biol Chem 2007, 282(32):23482-23490.

165. Liu X, Yamada N, Osawa T: Assessing the neuroprotective effect of antioxidant food factors by application of lipid-derived dopamine modification adducts. Methods Mol Biol 2010, 594:263-273.

166. Fukui K, Ushiki K, Takatsu H, Koike T, Urano S: Tocotrienols prevent hydrogen peroxide-induced axon and dendrite degeneration in cerebellar granule cells. Free Radic Res 2012, 46(2):184-193.

167. Liu X, Yamada N, Osawa T: Assessing the neuroprotective effect of antioxidative food factors by application of lipid-derived dopamine modification adducts. Methods Mol Biol 2009, 580:143-152.

168. Sen CK, Rink C, Khanna S: Palm oil-derived natural vitamin $E$ alpha-tocotrienol in brain health and disease. J Am Coll Nutr 2010, 29(3 Suppl):314S-323S

169. Sen CK, Khanna S, Rink C, Roy S: Tocotrienols: the emerging face of natural vitamin E. Vitam Horm 2007, 76:203-261.

170. Park HA, Kubicki N, Gnyawali S, Chan YC, Roy S, Khanna S, Sen CK: Natural vitamin $\mathrm{E}$ a-tocotrienol protects against ischemic stroke by induction of multidrug resistance-associated protein 1. Stroke 2011, 42(8):2308-2314.
171. Tiwari V, Kuhad A, Chopra K: Tocotrienol ameliorates behavioral and biochemical alterations in the rat model of alcoholic neuropathy. Pain 2009, 145(1-2):129-135.

172. Tiwari V, Kuhad A, Chopra K: Suppression of neuro-inflammatory signaling cascade by tocotrienol can prevent chronic alcohol-induced cognitive dysfunction in rats. Behav Brain Res 2009, 203(2):296-303.

173. Hermizi H, Faizah O, Ima-Nirwana S, Ahmad Nazrun S, Norazlina M Beneficial effects of tocotrienol and tocopherol on bone histomorphometric parameters in Sprague-Dawley male rats after nicotine cessation. Calcif Tissue Int 2009, 84(1):65-74.

174. Norazlina M, Hermizi H, Faizah O, Nazrun AS, Norliza M, Ima-Nirwana S: Vitamin $E$ reversed nicotine-induced toxic effects on bone biochemical markers in male rats. Arch Med Sci 2010, 6(4):505-512.

175. Mehat MZ, Shuid AN, Mohamed N, Muhammad N, Soelaiman IN: Beneficial effects of vitamin $E$ isomer supplementation on static and dynamic bone histomorphometry parameters in normal male rats. J Bone Miner Metab 2010, 28(5):503-509.

176. Shuid AN, Mehat Z, Mohamed N, Muhammad N, Soelaiman IN: Vitamin E exhibits bone anabolic actions in normal male rats. J Bone Miner Metab 2010, 28(2):149-156.

177. Maniam S, Mohamed N, Shuid AN, Soelaiman IN: Palm tocotrienol exerted better antioxidant activities in bone than alpha-tocopherol. Basic Clin Pharmacol Toxicol 2008, 103(1):55-60.

178. Norazlina M, Ima-Nirwana S, Abul Gapor MT, Abdul Kadir Khalid B: Tocotrienols are needed for normal bone calcification in growing female rats. Asia Pac J Clin Nutr 2002, 11(3):194-199.

179. Ima-Nirwana S, Kiftiah A, Sariza T, Gapor MT, Khalid BA: Palm vitamin E improves bone metabolism and survival rate in thyrotoxic rats. Gen Pharmacol 1999, 32(5):621-626.

180. Ima-Nirwana S, Suhaniza S: Effects of tocopherols and tocotrienols on body composition and bone calcium content in adrenalectomized rats replaced with dexamethasone. J Med Food 2004, 7(1):45-51.

181. Abdul-Majeed S, Mohamed N, Soelaiman IN: Effects of tocotrienol and lovastatin combination on osteoblast and osteoclast activity in estrogen-deficient osteoporosis. Evid Based Complement Alternat Med 2012, 2012:960742.

182. Soelaiman IN, Ming W, Abu Bakar R, Hashnan NA, Mohd Ali H, Mohamed N, Muhammad N, Shuid AN: Palm tocotrienol supplementation enhanced bone formation in oestrogen-deficient rats. Int J Endocrinol 2012 2012:532862.

183. Azlina MF, Nafeeza MI, Khalid BA: A comparison between tocopherol and tocotrienol effects on gastric parameters in rats exposed to stress. Asia Pac J Clin Nutr 2005, 14(4):358-365.

184. Nafeeza MI, Kang TT: Synergistic effects of tocopherol, tocotrienol, and ubiquinone in indomethacin-induced experimental gastric lesions. Int J Vitam Nutr Res 2005, 75(2):149-155

185. Ong FB, Wan Ngah WZ, Top AG, Khalid BA, Shamaan NA: Vitamin E, glutathione $S$-transferase and gamma-glutamyl transpeptidase activities in cultured hepatocytes of rats treated with carcinogens. Int J Biochem 1994, 26(3):397-402.

186. Brigelius-Flohe R: Induction of drug metabolizing enzymes by vitamin $\mathrm{E}$. J Plant Physiol 2005, 162(7):797-802.

187. Zhou C, Tabb MM, Sadatrafiei A, Grün F, Blumberg B: Tocotrienols activate the steroid and xenobiotic receptor, SXR, and selectively regulate expression of its target genes. Drug Metab Dispos 2004, 32(10):1075-1082.

188. Bhatti GK, Bhatti JS, Kiran R, Sandhir R: Alterations in $\mathrm{Ca}^{2+}$ homeostasis and oxidative damage induced by ethion in erythrocytes of Wistar rats: ameliorative effect of vitamin E. Environ Toxicol Pharmacol 2011 , 31(3):378-386

189. Bhatti GK, Bhatti JS, Kiran R, Sandhir R: Biochemical and morphological perturbations in rat erythrocytes exposed to ethion: protective effect of vitamin E. Cell Mol Biol (Noisy-le-Grand) 2011, 57(1):70-79.

190. Patel V, Rink C, Gordillo GM, Khanna S, Gnyawali U, Roy S, Shneker B, Ganesh K, Phillips G, More JL, Sarkar A, Kirkpatrick R, Elkhammas EA, Klatte E, Miller M, Firstenberg MS, Chiocca EA, Nesaretnam K, Sen CK: Oral tocotrienols are transported to human tissues and delay the progression of the model for end-stage liver disease score in patients. J Nutr 2012 142(3):513-519.

191. Yoshida M, Kimura H, Kyuki K, Ito M: Effect of combined vitamin E and insulin administration on renal damage in diabetic rats fed a high cholesterol diet. Biol Pharm Bull 2005, 28(11):2080-2086. 
192. Gupta A, Chopra K: Effect of tocotrienols on iron-induced renal dysfunction and oxidative stress in rats. Drug Chem Toxicol 2009, 32(4):319-325

193. Khan MR, Siddiqui S, Parveen K, Javed S, Diwakar S, Siddiqui WA Nephroprotective action of tocotrienol-rich fraction (TRF) from palm oil against potassium dichromate (K2Cr2O7)-induced acute renal injury in rats. Chem Biol Interact 2010, 186(2):228-238.

194. Budin SB, Han KJ, Jayusman PA, Taib IS, Ghazali AR, Mohamed J: Antioxidant activity of tocotrienol rich fraction prevents fenitrothion-induced renal damage in rats. J Toxic Pathol 2013 26(2):111-118

195. Nowak G, Bakajsova D, Hayes C, Hauer-Jensen M, Compadre CM: Gamma-Tocotrienol protects against mitochondrial dysfunction and renal cell death. J Pharmacol Exp Ther 2012, 340(2):330-338.

196. Arrand JE, Michael BD: Recent advances in the study of ionizing radiation damage and repair. Int J Rad Biol 1992, 61(6):717-720.

197. Multhoff $G$, Radons J: Radiation, inflammation, and immune responses in cancer. Front Oncol 2012, 2:58.

198. Roos WP, Kaina B: DNA damage-induced cell death by apoptosis. Trend Mol Med 2006, 12(9):440-450.

199. Cheung BMY, Li C: Diabetes and hypertension: is there a common metabolic pathway? Curr Atherosclerosis Rep 2012, 14(2):160-166.

200. Dumont F, Roux AL, Bischoff P: Radiation countermeasure agents: an update. Exp Opinion Therp Patent 2010, 1:73-101.

201. Kulkarni S, Ghosh SP, Hauer-Jensen M, Kumar KS: Hematological targets of radiation damage. Curr Drug Target 2010, 11(11):1375-1385

202. Farese AM, Herodin F, McKearn JP, Baum C, Burton E, MacVittie TJ: Acceleration of hematopoietic reconstitution with a synthetic cytokine (SC-55494) after radiation-induced bone marrow aplasia. Blood 1996, 87(2):581-591.

203. Ghosh SP, Kulkarni S, Hieber K, Toles R, Romanyukha L, Kao TC, Hauer-Jensen M, Kumar KS: Gamma-tocotrienol, a tocol antioxidant as a potent radioprotector. Int J Rad Biol 2009, 85(7):598-606.

204. Kulkarni S, Ghosh SP, Satyamitra M, Mog S, Hieber K, Romanyukha L, Gambles K, Toles R, Kao TC, Hauer-Jensen M, Kumar KS: Gamma-tocotrienol protects hematopoietic stem and progenitor cells in mice after total-body irradiation. Rad Res 2010, 173(6):738-747.

205. Berbée M, Fu Q, Boerma M, Wang J, Kumar KS, Hauer-Jensen M: $\gamma$-Tocotrienol ameliorates intestinal radiation injury and reduces vascular oxidative stress after total-body irradiation by an HMG-CoA Reductase-dependent mechanism. Rad Res 2009, 171(5):596-605.

206. Kulkarni SS, Cary LH, Gambles K, Hauer-Jensen M, Kumar KS, Ghosh SP: Gamma-tocotrienol, a radiation prophylaxis agent, induces high levels of granulocyte colony stimulating factor. Int Immunopharmacol 2012 14(4):495-503

207. Laufs U, La Fata V, Plutzky J, Liao JK: Upregulation of endothelial nitric oxide synthase by HMG CoA reductase inhibitors. Circulation 1998 97:1129-1135

208. Takemoto M, Liao JK: Pleiotropic effects of 3-hydroxy-3-methylglutaryl coenzyme A reductase inhibitors. Arterioscler Thromb Vasc Biol 2001, 21:1712-1719.

209. Kulkarni S, Chakraborty K, Kumar KS, Kao TC, Hauer-Jensen M, Ghosh SP: Synergistic radioprotection by gamma-tocotrienol and pentoxifylline: role of CAMP signaling. ISRN Radiol 2013. epub ehead of print.

210. Kim NY, Pae HO, Kim YC, Choi CK, Rim JS, Lee HS, Kim YM, Chung HT: Pentoxifylline potentiates nitric oxide production in interleukin-1betastimulated vascular smooth muscle cells through cyclic AMP-dependent protein kinase A pathway. Gen Pharmacol 2000, 35:205-211.

211. Zhang XP, Tada $H$, Wang Z, Hintze TH: CAMP signal transduction, a potential compensatory pathway for coronary endothelial NO production after heart failure. Arterioscler Thromb Vasc Biol 2002, 22:1273-1278.

212. Zhang $X P$, Hintze TH: cAMP signal transduction induces eNOS activation by promoting PKB phosphorylation. Am J Physiol Heart Circ Physiol 2006, 290:H2376-H2384.

213. Ernst E: Pentoxifylline for intermittent claudication: a critical review. Angiology 1994, 45(5):339-345.

214. Dettelbach HR, Aviado DM: Clinical pharmacology of pentoxifylline with special reference to its hemorrheologic effect for the treatment of intermittent claudication. J Clin Pharmacol 1985, 25(1):8-26.
215. Haddad P, Kalaghchi B, Amouzegar-Hashemi F: Pentoxifylline and vitamin E combination for superficial radiation induced fibrosis: a phase II clinical trial. Radiother Oncol 2005, 77(3):324-326.

216. Amano M, Monzen H, Suzuki M, Terai K, Andoh S, Tsumuraya A, Hasegawa T: Increase in tumor oxygenation and potentiation of radiation effects using pentoxifylline, vinpocetine and ticlopidine hydrochloride. J Rad Res 2005, 46(4):373-378

217. Dion MW, Hussey DH, Osborne JW: The effect of pentoxifylline on early and late radiation injury following fractionated irradiation in $\mathrm{C} 3 \mathrm{H}$ mice. Int J Rad Oncol Biol Phy 1989, 17(1):101-107.

218. Rübe CE, Wilfert F, Uthe D, Schmid KW, Knoop R, Willich N, Schuck A, Rübe $C$ : Modulation of radiation induced tumour necrosis factor $a$ (TNF- $a$ ) expression in the lung tissue by pentoxifylline. Radiother Oncol 2002, 64(2):177-187.

219. Berbée M, Fu Q, Garg S, Kulkarni S, Kumar KS, Hauer-Jensen M: Pentoxifylline enhances the radioprotective properties of $\gamma$-Tocotrienol: differential effects on the hematopoietic, gastrointestinal and vascular systems. Rad Res 2011, 175(3):297-306.

220. Nakamura H, Furukawa F, Nishikawa A, Miyauchi M, Son HY, Imazawa T, Hirose M: Oral toxicity of a tocotrienol preparation in rats. Food Chem Toxicol 2001, 39(8):799-805

221. Fu JY, Che HL, Tan DM, Teng KT: Bioavailability of tocotrienols: evidence in human studies. Nutr Metab 2014, 11:p5.

222. Campbell SE, Rudder B, Phillips RB, Whaley SG, Stimmel JB, Leesnitzer LM, Lightner J, Dessus-Babus S, Duffourc M, Stone WL, Menter DG, Newman RA, Yang P, Aggarwal BB, Krishnan K: Gamma-Tocotrienol induces growth arrest through a novel pathway with TGFbeta2 in prostate cancer. Free Radic Biol Med 2011, 50(10):1344-1354.

223. Park SK, Sanders BG, Kline K: Tocotrienols induce apoptosis in breast cancer cell lines via an endoplasmic reticulum stress-dependent increase in extrinsic death receptor signaling. Breast Cancer Res Treat 2010, 124(2):361-375.

224. Shah S, Sylvester PW: Tocotrienol-induced caspase- 8 activation is unrelated to death receptor apoptotic signaling in neoplastic mammary epithelial cells. Exp Biol Med (Maywood) 2004, 229(8):745-755.

225. Shah S, Gapor A, Sylvester PW: Role of caspase-8 activation in mediating vitamin E-induced apoptosis in murine mammary cancer cells. Nutr Cancer 2003, 45(2):236-246.

doi:10.1186/1743-7075-11-52

Cite this article as: Ahsan et al.: Pharmacological potential of tocotrienols: a review. Nutrition \& Metabolism 2014 11:52

\section{Submit your next manuscript to BioMed Central and take full advantage of:}

- Convenient online submission

- Thorough peer review

- No space constraints or color figure charges

- Immediate publication on acceptance

- Inclusion in PubMed, CAS, Scopus and Google Scholar

- Research which is freely available for redistribution

Submit your manuscript at www.biomedcentral.com/submit
C Biomed Central 